\title{
A Brief Review of the Effects of Pressure on Wolframite-Type Oxides
}

\author{
Daniel Errandonea ${ }^{1, *(1)}$ and Javier Ruiz-Fuertes ${ }^{1,2}$ \\ 1 Departament de Física Aplicada-ICMUV, MALTA Consolider Team, Universitat de València, 46100 Burjassot, \\ Spain; ruizfuertesj@unican.es \\ 2 DCITIMAC, MALTA Consolider Team, Universidad de Cantabria, 39005 Santander, Spain \\ * Correspondence: daniel.errandonea@uv.es; Tel.: +34-96-354-4475
}

Received: 8 January 2018; Accepted: 29 January 2018; Published: 31 January 2018

\begin{abstract}
In this article, we review the advances that have been made on the understanding of the high-pressure (HP) structural, vibrational, and electronic properties of wolframite-type oxides since the first works in the early 1990s. Mainly tungstates, which are the best known wolframites, but also tantalates and niobates, with an isomorphic ambient-pressure wolframite structure, have been included in this review. Apart from estimating the bulk moduli of all known wolframites, the cation-oxygen bond distances and their change with pressure have been correlated with their compressibility. The composition variations of all wolframites have been employed to understand their different structural phase transitions to post-wolframite structures as a response to high pressure. The number of Raman modes and the changes in the band-gap energy have also been analyzed in the basis of these compositional differences. The reviewed results are relevant for both fundamental science and for the development of wolframites as scintillating detectors. The possible next research avenues of wolframites under compression have also been evaluated.
\end{abstract}

Keywords: wolframite; high pressure; phase transitions; crystal structure; phonons; band structure

\section{Introduction}

Wolframite is an iron manganese tungstate mineral. The name is normally used to denote the family of isomorphic compounds. The crystal structure of a wolframite was first solved for $\mathrm{MgWO}_{4}$ by Broch [1] in 1929 with the exception of the oxygen positions and then completely determined for $\mathrm{NiWO}_{4}$ by Keeling [2] in 1957. The structure of wolframite, monoclinic with space group $P 2 / c$, is adopted by all tungstates $A \mathrm{WO}_{4}$ with the divalent cation $A$ with an ionic radius in octahedral coordination $r_{A}<0.9 \AA$. In addition, $\mathrm{CdWO}_{4}$, both $M=$ In and Sc niobates $M \mathrm{NbO}_{4}$ and tantalates $M \mathrm{MaO}_{4}$, and a metastable high-pressure (HP) and high-temperature polymorph in molybdates $A \mathrm{MoO}_{4}$ [3] have an isostructural crystal structure. Most wolframites, and in particular tungstates and molybdates with an $A^{2+}$ cation with a completely empty or full outer $d$ shell, have been extensively studied for their applications in scintillating detectors for X-ray tomography, high-energy particle physics, and dosimetry devices [4-6]. The reason behind this is their high light yield when hit by $\gamma$-particles or $X$-rays despite long scintillation times of a few $\mu$ s [7]. In fact, the search for different polymorphs of the scintillating wolframites with enhanced properties, i.e., a faster scintillating response, has motivated the study of these materials under high pressure conditions. In addition, wolframites with transition metals with unfilled outer $d$-shells are magnetic. In particular, hübnerite $\mathrm{MnWO}_{4}$, which shows three different antiferromagnetic phases below $13.7 \mathrm{~K}$, is a type II multiferroic material [8,9], exhibiting ferroelectricity induced by helical magnetic ordering.

After the pioneering work of Young and Schwartz [3], dated from 1963, in which the synthesis of different wolframite-type molybdates was reported at $\sim 0.6 \mathrm{GPa}$ and $900{ }^{\circ} \mathrm{C}$, only two works were 
published about the HP behavior of wolframites during the 1990s. A detailed structural study of the wolframite structure of $\mathrm{MgWO}_{4}, \mathrm{MnWO}_{4}$, and $\mathrm{CdWO}_{4}$ was performed at room temperature by Macavei and Schultz [10] up to 9.3 GPa using single crystal X-ray diffraction (XRD). A Raman spectroscopy study of $\mathrm{CdWO}_{4}$ at up to $\sim 40 \mathrm{GPa}$ was carried out by Jayaraman et al. [11] in which a structural phase transition of $\mathrm{CdWO}_{4}$ was found at $20 \mathrm{GPa}$. However, during the last decade, the interest in the behavior of wolframites under high pressure has inspired many works that have contributed to our understanding of their structural [12-16], vibrational [15-21], and electronic [14,22] properties under compression.

In the following sections, we shall review first the main features of the behavior and trends of the structure of wolframites under high pressure and the advances on the structural determination of their HP phases. Finally, the effects of pressure on the vibrational, electronic, and optical properties shall be presented with a special emphasis on $\mathrm{CdWO}_{4}$, whose $\mathrm{HP}$ phase has recently been fully solved.

\section{The Wolframite Structure at High Pressure}

The best description of the wolframite structure at ambient pressure was formulated by Kihlborg and Gebert [23] in 1969, unfolding the structure of the Jahn-Teller distorted $\mathrm{CuWO}_{4}$ wolframite. The wolframite structure of an $A \mathrm{XO}_{4}$ compound at ambient conditions (Figure 1a) can be described as a framework of oxygen atoms in approximately hexagonal close packing with the cations $(A$ and $X=W)$, octahedrally coordinated and occupying half of the octahedral sites. In this structure, the octahedral units of the same cations share edges forming alternating zig-zag chains and conferring the structure with a layer-like $A O X O$ configuration in the [100] direction. A particular case worth mentioning is $\mathrm{CuWO}_{4}$, not included in the list of wolframites presented in the introduction. Although, according to the ionic radius of $\mathrm{Cu}$, it should also crystallize in the same structure as $\mathrm{NiWO}_{4}$ and $\mathrm{ZnWO}_{4}$, it does it in a distorted version of the wolframite structure. In $\mathrm{CuWO}_{4}$, as a consequence of the Jahn-Teller effect of $\mathrm{Cu}^{2+}$ in octahedral coordination [23,24], the $\mathrm{Cu}^{2+}$ ion requires a distortion that is achieved by a shear parallel to the $b$-axis along each copper plane. This has as a consequence a displacement of oxygen layers, destroying the twofold symmetry and lowering the space group from $P 2 / c$ to $P \overline{1}$.

(a)

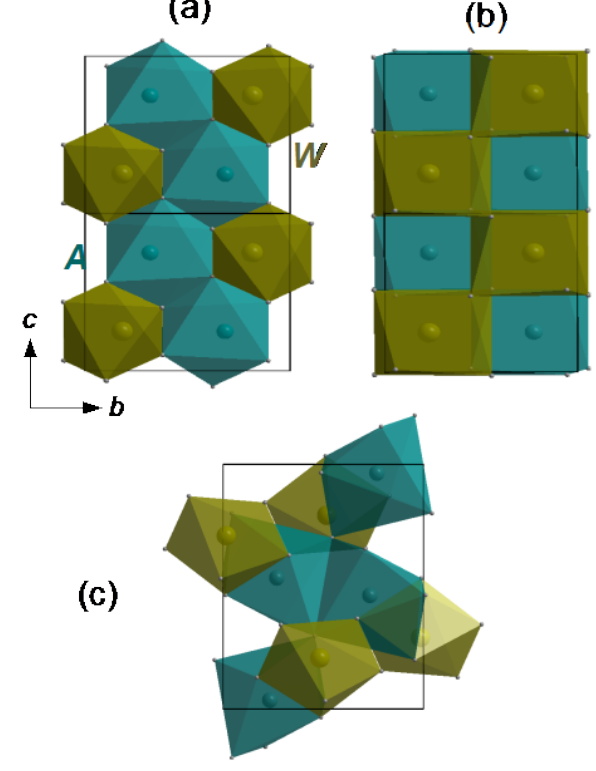

Figure 1. (a) General ambient-pressure wolframite-type structure of $A X \mathrm{O}_{4}(X=\mathrm{W})$ compounds and high-pressure (HP) structure of (b) $\mathrm{InTaO}_{4}$ and (c) $\mathrm{CdWO}_{4}$. In (a), the coordination polyhedra of the divalent cation $A(\mathrm{~W})$ are shown in green (turquoise). In (b), the same color code is used for In and Ta polyhedra, respectively. In (c), Cd (W) polyhedra are shown in green (turquoise). 
In wolframites, the monoclinic $a$ and $c$ unit-cell lattice parameters are similar, although the $c$-axis is slightly larger than the $a$-axis. However, the $b$-axis is, in general, around $15 \%$ larger than the other axes. The monoclinic angles are always very close to $90^{\circ}$. As was first shown by Macavei and Shultz [10] in $\mathrm{MgWO}_{4}, \mathrm{MnWO}_{4}$, and $\mathrm{CdWO}_{4}$, this causes the wolframite structure to suffer an anisotropic contraction under pressure (Figure 2). For instance, in $\mathrm{MnWO}_{4}$ [13], the axial compressibility (defined as $\left.k_{\mathrm{x}}=(-1 / \mathrm{x}) \times \partial \mathrm{x} / \partial \mathrm{P}\right)$ of the $b$-axis $\left(k_{\mathrm{b}}=3.3(1) \times 10^{-3} \mathrm{GPa}^{-1}\right)$ almost doubles the axis compressibility of $a$ and $c\left(k_{\mathrm{a}}=2.0(1) \times 10^{-3} \mathrm{GPa}^{-1}\right.$ and $\left.k_{\mathrm{c}}=1.6(1) \times 10^{-3} \mathrm{GPa}^{-1}\right)$. The same anisotropic compression has been found in $\mathrm{CdWO}_{4}, \mathrm{MgWO}_{4}$, and other wolframites [10-14]. This fact, together with a continuous increase in the monoclinic $\beta$ angle, indicates that, under compression, the monoclinic structure tends to distort, at least in tungstates. We shall show in the next section that this continuous distortion causes a phase transition to a structure with a lower symmetry in most wolframite-type tungstates. The only exception is $\mathrm{CdWO}_{4}$, which increases its space-group symmetry at the phase transition. In the structure of wolframite, the octahedra of different cations only share corners between them, while octahedra of the same cation share both corners and edges. Hence, we can isolate the $A \mathrm{O}_{6}$ and $\mathrm{XO}_{6}$ polyhedral units as independent blocks in the structure. In this picture, each type of polyhedra would respond differently to the effect of pressure. In particular, one would expect the $\mathrm{XO}_{6}$, with high valence $\left(6^{+}\right.$in $\mathrm{W}$ or Mo, and $5^{+}$in Ta or $\left.\mathrm{Nb}\right)$ to be much less compressible than the $A$ cations with $2^{+}$or $3^{+}$valences. Such an approach has often been used to study the bulk compressibility of scheelites, a structure adopted by tungstates with $A$ cations with a large ionic radius. However, differently from wolframites, in scheelites, the also-isolated $X$ cations are tetrahedrally coordinated. Therefore, the $\mathrm{XO}_{4}$ polyhedra are almost pressure-independent, and the bulk modulus is very well predicted by the empirical equation $B_{0}=\mathrm{N} \cdot \mathrm{Z} / d_{\mathrm{A}-\mathrm{O}}{ }^{3}$, first proposed by Hazen and Finger [25], which assumes that the bulk modulus is proportional ( $\mathrm{N}$ being the proportion constant) to the formal charge of the $A$ cation, $Z$, and inversely proportional to the cation-anion distance to the third power $d_{\mathrm{A}-\mathrm{O}}{ }^{3}$. In the case of scheelites, this proportion constant is $N=610$ [26]. The question is how such a model would work for wolframites. In Figure 3, we show the estimated and experimentally available bulk modulus of all known wolframites. The agreement is excellent considering $\mathrm{N}=661$ for wolframite-type tungstates and molybdates and $\mathrm{N}=610$ for tantalates and niobates, indicating that assuming that the $\mathrm{XO}_{6}$ in wolframites is a rigid and almost pressure-incompressible unit is justified in terms of the bulk modulus. In Section 4, we shall study how this approximation works in terms of describing the Grüneisen parameters of the Raman-active modes. The experimental bulk modulus values are shown in Table 1. Figure 3 also shows that the bulk moduli of tantalates and niobates is around $30 \%$ larger than the bulk modulus of tungstates. This fact, a result of a higher valence of the $A$ cation $\left(3^{+}\right.$instead of $2^{+}$), reinforces the negligible effect of pressure on the $\mathrm{XO}_{6}$ polyhedra since the empirical formula is also valid despite the valence of $\mathrm{Ta}$ and $\mathrm{Nb}$ is $5^{+}$instead of $6^{+}$.

Table 1. Experimental bulk modulus $\left(B_{0}\right)$ of different wolframites. Results were obtained from [10] and [12-16].

\begin{tabular}{ccc}
\hline Compounds & $\boldsymbol{B}_{\mathbf{0}}(\mathrm{GPa})$ & Reference \\
\hline $\mathrm{MgWO}_{4}$ & $144-160$ & {$[10,12]$} \\
$\mathrm{MnWO}_{4}$ & $131-145$ & {$[10,13]$} \\
$\mathrm{ZnWO}_{4}$ & 145 & {$[12]$} \\
$\mathrm{CdWO}_{4}$ & $136-123$ & {$[10,14]$} \\
$\mathrm{InTaO}_{4}$ & 179 & {$[15]$} \\
$\mathrm{InNbO}_{4}$ & 179 & {$[16]$} \\
\hline
\end{tabular}




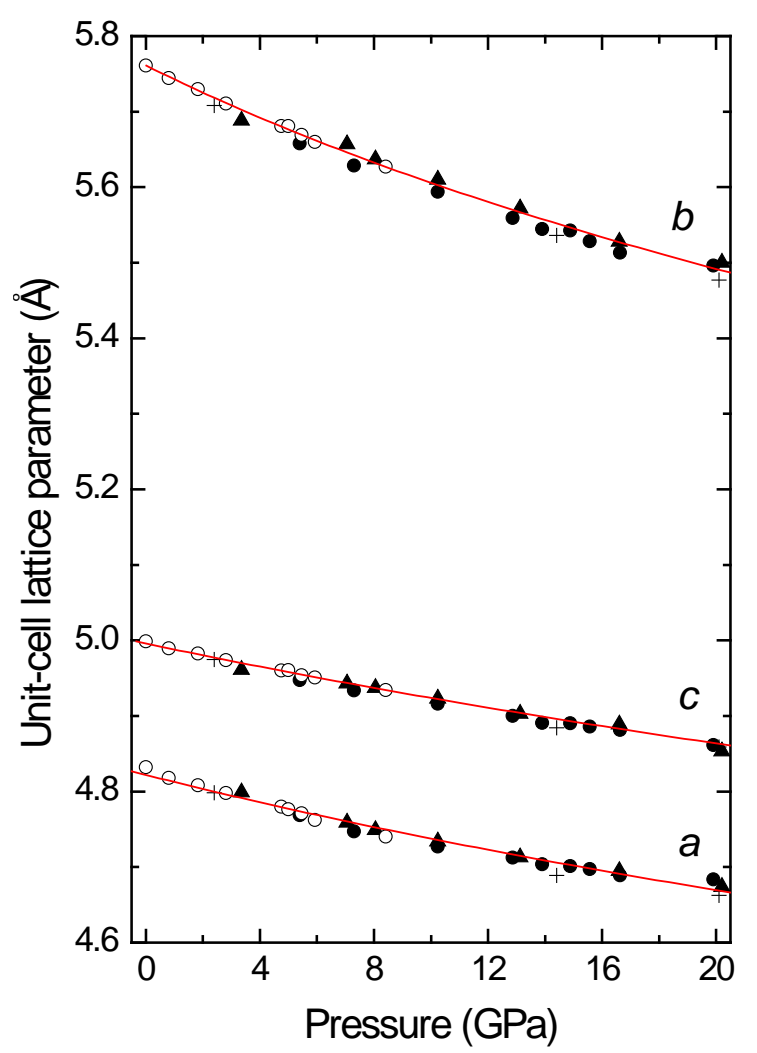

Figure 2. Pressure dependence of the unit-cell lattice parameters of $\mathrm{MnWO}_{4}$. Empty circles represent Macavei's and Schulz's data [10], full circles and triangles represent data obtained by powder X-ray diffraction, and the crosses represent data obtained by single crystal X-ray diffraction [14]. The continuous lines are fits to a third-order Birch-Murnaghan equation of state.

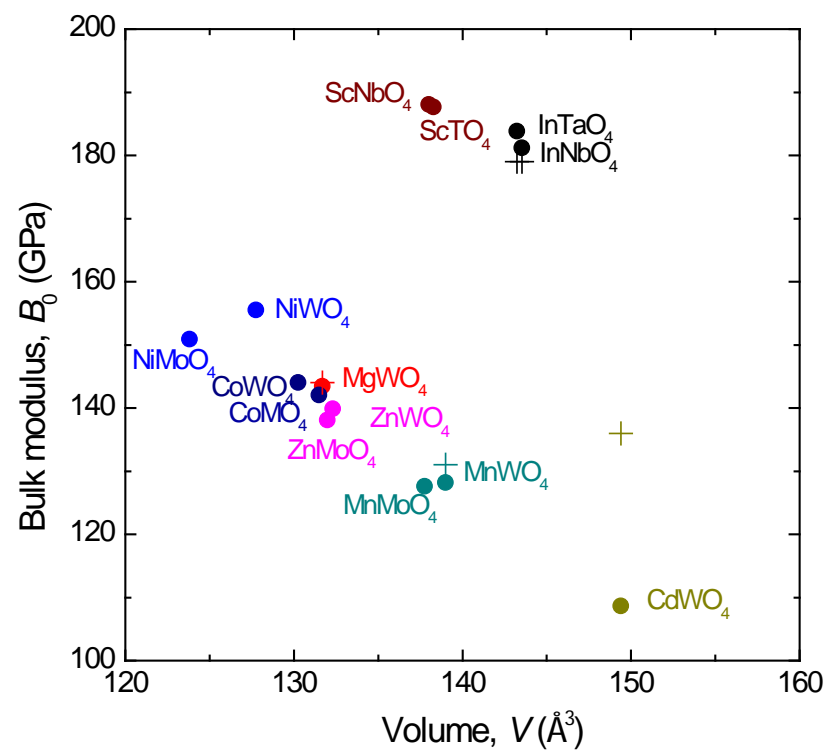

Figure 3. Volume change of the bulk modulus $B_{0}$ of all known compounds with a wolframite-type structure. Crosses $(+)$ represent experimental results. Circles are the estimated $B_{0}$ considering the $\mathrm{WO}_{6}, \mathrm{MoO}_{6}, \mathrm{TaO}_{6}$, and $\mathrm{NbO}_{6}$ as rigid units and the following dependence with the A-O distances: $B_{0}=610 \cdot \mathrm{Z} / d_{\mathrm{A}-\mathrm{O}}{ }^{3}$ in the case of tantalates and niobates and $B_{0}=661 \cdot \mathrm{Z} / d_{\mathrm{A}-\mathrm{O}}{ }^{3}$ in the case of tungstates and molybdates. Different colors are used for different compounds, the same color being used for the compound name. 
Regarding the atomic positions under compression in wolframites, while the oxygen atoms barely change their positions, the cations tend to shift along the high symmetry $b$-axis [10]; the $A$ cations either shift down or up depending on the compound, but the $W$ cations largely shift down along the $b$-axis. For tantalates and niobates, no reliable atomic positions exist under pressure.

\section{Phase Transitions}

Under compression, most wolframites undergo a phase transformation to a different polymorph, with tungstates transiting at around $20 \mathrm{GPa}$, and $\mathrm{InTaO}_{4}$ and $\mathrm{ScNbO}_{4}$ doing so a few GPa below. However, the post-wolframite phase depends on the compound. Thus, while tungstates, except $\mathrm{CdWO}_{4}$, apparently transform to a triclinic version of wolframites, similar to that of $\mathrm{CuWO}_{4}$, with space group $P \overline{1}$ and a similar unit-cell, tantalates and niobates also do it but to another distorted version of wolframite that keeps the same space group $P 2 / c$. $\mathrm{CuWO}_{4}$ and $\mathrm{CdWO}_{4}$ are the only (pseudo)wolframites that, under pressure, increase their space-group symmetry, with $\mathrm{CuWO}_{4}$ transforming to a normal wolframite structure with space group $P 2 / c$, despite keeping the Jahn-Teller distortion, and $\mathrm{CdWO}_{4}$ introducing a screw axis in space group $P 2_{1} / c$ and doubling the unit cell. The solution of the HP phase of the tungstates has been approached unsuccessfully with powder X-ray diffraction in $\mathrm{ZnWO}_{4}$ and $\mathrm{MgWO}_{4}$ [12] and with single crystal X-ray diffraction in $\mathrm{MnWO}_{4}$ [13]. However, based on the careful indexation of the observed reflections, the study of the systematic extinctions of the HP phase, and the number of active Raman modes observed in the HP phase, which we shall show in the next section, a triclinic structure is proposed as the post-wolframite structure of normal wolframites. This proposed post-wolframite structure would be very similar to the low-pressure phase, but would be described as being in space group $P \overline{1}$. Unfortunately, in the particular case of $\mathrm{MnWO}_{4}$, the single crystal, despite of a small volume collapse of only $1 \%$ in the phase transition, dramatically deteriorates (Figure 4) with the appearance of more than two triclinic HP domains during the phase transition coexisting with the monoclinic low-pressure phase. This fact prevents a correct integration of the reflection intensities and therefore an accurate determination of the atomic positions in the $\mathrm{HP}$ phase. Since the experiments in $\mathrm{MnWO}_{4}$ were carried out using $\mathrm{Ne}$ as a pressure-transmitting medium, the phase coexistence observed is likely inherent to the properties of the sample and not caused by non-hydrostatic effects. The study of this issue deserves future efforts.
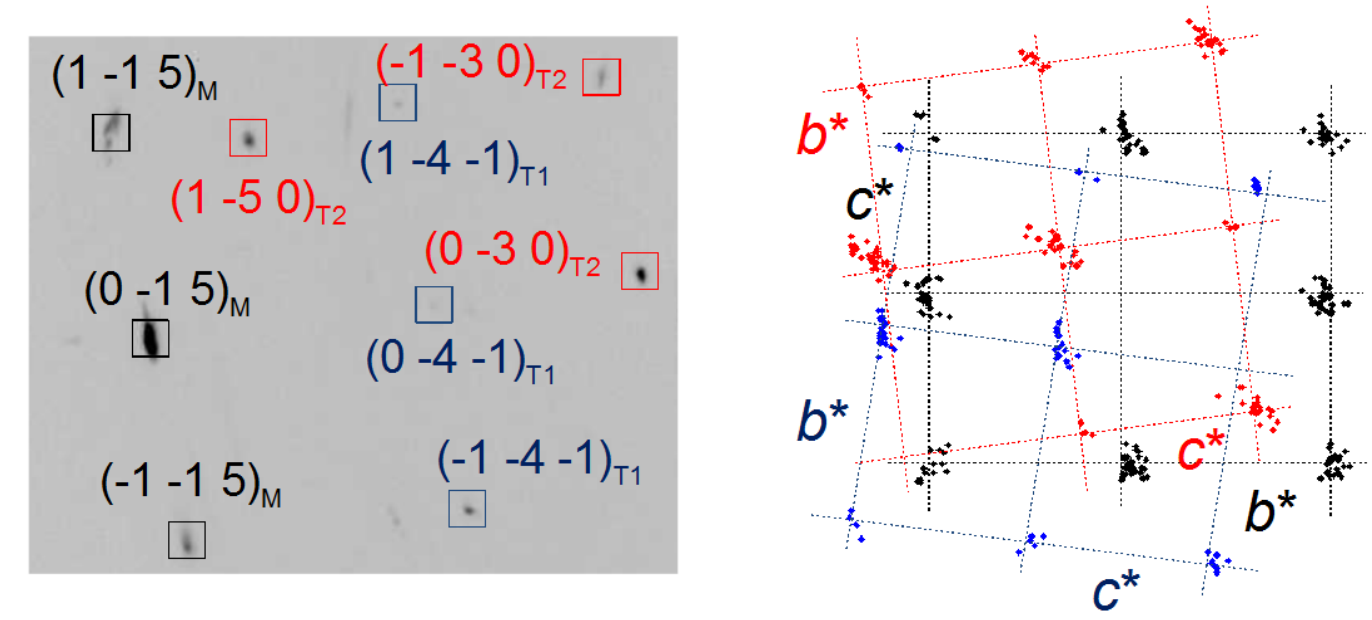

Figure 4. Section of one single-crystal X-ray diffraction frame of $\mathrm{MnWO}_{4}$ (left) showing the existence of the reflections of two HP triclinic domains (T1, T2) along the monoclinic (M) reflections. The corresponding projection of the reciprocal space on the $\left(b^{*} ; c^{*}\right)$ plane (right). Dots represent the location of the measured reflections projected along the $a^{*}$-axis. The axes of the unit cells are shown as dashed lines. The monoclinic reflections are in black, while the triclinic reflections of the two domains are in blue (T1) and red (T2). 
In the previous section, we mentioned that $\mathrm{CdWO}_{4}$, with $\mathrm{Cd}$ having an ionic radius in octahedral coordination above $0.9 \AA$, is just above the limit to be a wolframite at ambient pressure. This implies that the $\mathrm{Cd}-\mathrm{O}$ distances are larger than the $A-\mathrm{O}$ distances in the remaining wolframites and that its bulk modulus is therefore the lowest one in the series (Figure 3). In the extreme case of $\mathrm{MgWO}_{4}$, the $\mathrm{Cd}-\mathrm{O}$ distances are around $12 \%$ longer than the $\mathrm{Mg}-\mathrm{O}$ distances and the bulk modulus of $\mathrm{MgWO}_{4}$ is $25 \%$ larger than that of $\mathrm{CdWO}_{4}$. These differences have an influence in the phase transition of $\mathrm{CdWO}_{4}$ that emerge for instance in the Raman spectrum of the HP phase of $\mathrm{CdWO}_{4}$, presenting 36 instead of 18 modes observed in the post-wolframite phase of normal wolframites (Section 4). In fact, such an increase in modes relates to the doubling of the unit cell that the post-wolframite of $\mathrm{CdWO}_{4}$ presents above $20 \mathrm{GPa}$. The structure (Figure 1c) was solved with single-crystal X-ray diffraction at $20 \mathrm{GPa}$ [14]. According to Macavei and Shultz [10], the $y$ coordinate of Cd moves fast under pressure. In the phase transition, the $a$-axis of the HP unit cell remains in the [100] direction of the low-pressure cell, increasing its length, while the new [010] and [001] directions form from the [0 $\overline{1} 1]$ and [011] directions of the low-pressure wolframite cell, respectively. Such a transformation, which can

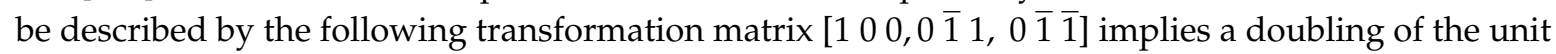
cell from $Z=2$ in the wolframite structure to the $Z=4$ of the post-wolframite of $\mathrm{CdWO}_{4}$. Such a phase transition gives rise to the formation of a screw axis in the [010] direction of the HP phase and therefore a space-group symmetry increase from $P 2 / c$ to $P 2_{1} / c$. Regarding the coordination of the tungsten and cadmium ions, it is increased to 7 -fold and $6+1$-fold, respectively, when the phase transition occurs (Figure 1c). This coordination increase contrasts with the phase transition undergone by normal wolframites, which keep the same octahedral coordination for both cations up to the highest pressure reached according to Raman spectroscopy in the case of the other tungstates. According to powder $X$-ray diffraction, a coordination increase occurs at the phase transition in tantalates and niobates as well $[15,16]$. Considering that the $\mathrm{Cd}-\mathrm{O}$ distances are abnormally large in the wolframite-type structure, the coordination increase associated with the phase transition relates well with $\mathrm{CdWO}_{4}$, which has a more compact and stable structure that differs more from the wolframite-type structure than the HP phase of the wolframite-type tungstates that keep the cationic coordination. This coordination change is directly related to a band-gap energy drop associated with the phase transition as we shall show in Section 4 [14].

In the case of $\mathrm{InTaO}_{4}$ and $\mathrm{InNbO}_{4}$, both compounds undergo phase transitions at 13 and $10.8 \mathrm{GPa}$, respectively. These are pressures around $10 \mathrm{GPa}$ below the phase transition of wolframite-type tungstates. This indicates that, when the $X$ cation is substituted by $\mathrm{Ta}$ or $\mathrm{Nb}$, the wolframite structure becomes less robust, probably, as the result of the lowering of the nominal charge of the ion and therefore weakening the $\mathrm{X}-\mathrm{O}$ bond. Under high pressure, $\mathrm{InTaO}_{4}$ and $\mathrm{InNbO}_{4}$ undergo the same phase transition to a structure (Figure 1 b) solved with powder X-ray diffraction $[15,16]$. Their post-wolframite structure consists on a packing of the wolframite-type structure with the $X$ cations increasing their coordination from 6 to 8 -fold filling the channels that the alternating $A \mathrm{OXO}$ zigzag chains create in the [001] direction in the wolframite structure. This alternating pattern is kept in the HP phase but with the $A$ and $X$ cations having an eight-fold coordination in the HP phase. The coordination increase in both kind of cations and the packing increase generate a different interaction between the $A \mathrm{O}_{8}$ and $\mathrm{XO}_{8}$ polyhedra that now share also edges in addition to corners between them. This implies that they cannot longer be considered as separated blocks.

In order to conclude this section, we shall comment on the case of $\mathrm{CuWO}_{4}$, which, though it presents a distorted triclinic version of the monoclinic wolframite structure at ambient pressure, also transforms to the monoclinic wolframite structure above $\sim 9 \mathrm{GPa}$ [23]. As we explained in the previous section, the low-pressure structure of $\mathrm{CuWO}_{4}$ is also formed by $\mathrm{CuO}_{6}$ and $\mathrm{WO}_{6}$ polyhedra arranged in a very similar way to wolframite. However, due to the degeneracy breaking of the $3 d^{9}$ orbitals of $\mathrm{Cu}^{2+}$ into five electronic levels (two singlets and one doublet) as a result of the Jahn-Teller effect, two of the six $\mathrm{Cu}-\mathrm{O}$ distances are longer than the other four, thus lowering its local structure from quasi $O_{h}$ to quasi $D_{4 h}$ symmetry. Under high pressure, the two longest $\mathrm{Cu}-\mathrm{O}$ distances reduce; however, before 
quenching the Jahn-Teller distortion, the system finds an easy distortion direction, and the elongated axes of the $\mathrm{CuO}_{6}$ polyhedra shift from the [111] in the low-pressure phase to the [101] in the HP phase. Thus, the structure transforms to a wolframite structure in space group $P 2 / c$ that still accommodates the Jahn-Teller distortion of $\mathrm{Cu}^{2+}$.

\section{Raman Spectroscopy}

Raman spectroscopy is a technique used to observe vibrational modes in a solid and is one of the most informative probes for studies of material properties under HP [24]. Since the study performed two decades ago by Fomichev et al. in $\mathrm{ZnWO}_{4}$ and $\mathrm{CdWO}_{4}$ [25], the Raman spectra of wolframite-type tungstates have been extensively characterized. Studies have been carried out for synthetic crystals [17-20] and minerals [26] and have been also performed for $\mathrm{InTaO}_{4}$ [15] and $\mathrm{InNbO}_{4}$ [16]; however, the characterization of the Raman-active vibrations in wolframite-type molybdates is missing. Indeed, the Raman spectra of $\mathrm{CoMoO}_{4}, \mathrm{MnMoO}_{4}$, and $\mathrm{MgMoO}_{4}$ have been characterized [27-29], but for polymorphs different from wolframite.

According to group-theory analysis, a crystal structure isomorphic to wolframite has 36 vibrational modes at the $\Gamma$ point of the Brillouin zone: $\Gamma=8 \mathrm{~A}_{\mathrm{g}}+10 \mathrm{~B}_{\mathrm{g}}+8 \mathrm{~A}_{\mathrm{u}}+10 \mathrm{~B}_{\mathrm{u}}$. Three of these vibrations correspond to acoustic modes $\left(A_{u}+2 B_{u}\right)$ and the rest are optical modes, 18 of which are Raman active $\left(8 \mathrm{~A}_{\mathrm{g}}+10 \mathrm{~B}_{\mathrm{g}}\right)$ and 15 of which are infrared active $\left(7 \mathrm{~A}_{\mathrm{u}}+8 \mathrm{~B}_{\mathrm{u}}\right)$. Typical Raman spectra, taken from the literature [17-20] of wolframite-type tungstates are shown in Figure 5. In the figure, it can be seen that the frequency distribution (and intensity) of the Raman-active modes is qualitatively similar in $\mathrm{CdWO}_{4}, \mathrm{ZnWO}_{4}, \mathrm{MnWO}_{4}$, and $\mathrm{MgWO}_{4}$. Since Raman-active vibrations correspond either to $\mathrm{A}_{\mathrm{g}}$ or $\mathrm{B}_{\mathrm{g}}$ modes, polarized Raman scattering and selection rules can be combined to identify the symmetry of modes [30,31]. The expected 18 Raman modes have been measured for $\mathrm{CdWO}_{4}, \mathrm{ZnWO}_{4}$, $\mathrm{MnWO}_{4}$, and $\mathrm{MgWO}_{4}$, and 15 modes for $\mathrm{CoWO}_{4}, \mathrm{FeWO}_{4}$, and $\mathrm{NiWO}_{4}$. The frequencies of the modes are summarized in Table 2. As we commented above, the frequency distribution of modes is similar in all tungstates, with 4 high-frequency modes, two isolated modes around $500-550 \mathrm{~cm}^{-1}$, and the remaining 12 modes at frequencies below $450 \mathrm{~cm}^{-1}$ in all of the compounds.

Table 2. Raman frequencies, $\omega\left(\mathrm{cm}^{-1}\right)$, measured in different wolframite-type tungstates [17-20]. The symmetry of the different modes is given. The pressure coefficients, $\mathrm{d} \omega / \mathrm{dP}\left(\mathrm{cm}^{-1} / \mathrm{GPa}\right)$, are included in parenthesis for those compounds that are available. The asterisks identify the internal modes of the $\mathrm{WO}_{6}$ octahedron.

\begin{tabular}{|c|c|c|c|c|c|c|c|}
\hline \multirow{2}{*}{ Mode } & $\mathrm{MgWO}_{4}$ & $\mathrm{MnWO}_{4}$ & $\mathrm{ZnWO}_{4}$ & $\mathrm{CdWO}_{4}$ & $\mathrm{FeWO}_{4}$ & $\mathrm{CoWO}_{4}$ & $\mathrm{NiWO}_{4}$ \\
\hline & $\omega(\mathrm{d} \omega / \mathrm{dP})$ & $\omega(\mathrm{d} \omega / \mathrm{dP})$ & $\omega(\mathrm{d} \omega / \mathrm{dP})$ & $\omega(\mathrm{d} \omega / \mathrm{dP})$ & $\omega$ & $\omega$ & $\omega$ \\
\hline $\mathrm{B}_{\mathrm{g}}$ & $97.4(0.69)$ & $89(0.73)$ & $91.5(0.95)$ & $78(0.52)$ & 86 & 88 & 91 \\
\hline$A_{g}$ & $155.9(0.26)$ & $129(0.02)$ & $123.1(0.65)$ & $100(0.69)$ & 124 & 125 & 141 \\
\hline $\mathrm{B}_{\mathrm{g}}$ & $185.1(0.51)$ & $160(0.22)$ & $145.8(1.20)$ & $118(1.02)$ & 154 & 154 & 165 \\
\hline $\mathrm{B}_{\mathrm{g}}$ & $215.0(0.63)$ & $166(0.78)$ & $164.1(0.72)$ & $134(0.82)$ & 174 & 182 & 190 \\
\hline $\mathrm{B}_{\mathrm{g}}^{\mathrm{s}}$ & $266.7(1.01)$ & $177(1.03)$ & $189.6(0.67)$ & $148(1.51)$ & & 199 & 201 \\
\hline$A_{g}$ & $277.1(0.55)$ & $206(2.01)$ & $196.1(2.25)$ & $177(0.71)$ & 208 & & \\
\hline $\mathrm{B}_{\mathrm{g}}$ & 313.9 (1.99) & $272(2.03)$ & $267.1(1.32)$ & $249(2.14)$ & 266 & 271 & 298 \\
\hline$A_{g}^{\delta}$ & $294.1(1.92)$ & $258(0.30)$ & $276.1(0.87)$ & $229(0.29)$ & & & 298 \\
\hline $\mathrm{B}_{\mathrm{g}}$ & $384.8(4.95)$ & $294(2.02)$ & $313.1(1.74)$ & $269(1.41)$ & 299 & 315 & \\
\hline$A_{g}^{0}$ & $351.9(3.52)$ & $327(1.50)$ & 342.1 (1.74) & $306(0.04)$ & 330 & 332 & 354 \\
\hline $\mathrm{B}_{\mathrm{g}}$ & $405.2(1.47)$ & $356(4.09)$ & 354.1 (3.87) & $352(4.55)$ & & & \\
\hline $\mathrm{A}_{\mathrm{g}^{*}}^{\delta}$ & $420.4(1.59)$ & $397(1.69)$ & 407 (1.65) & $388(2.33)$ & 401 & 403 & 412 \\
\hline $\mathrm{B}_{\mathrm{g}}^{8}$ & $518.1(3.30)$ & $512(2.86)$ & $514.5(3.18)$ & $514(3.86)$ & 500 & 496 & 505 \\
\hline $\mathrm{A}_{\mathrm{g}^{*}}$ & $551.6(3.00)$ & 545 (2.39) & $545.5(3.00)$ & $546(2.32)$ & 534 & 530 & 537 \\
\hline $\mathrm{B}_{\mathrm{g}^{*}}^{0}$ & $683.9(4.09)$ & $674(4.20)$ & $677.8(3.90)$ & $688(4.35)$ & 653 & 657 & 663 \\
\hline$A_{g^{*}}^{b}$ & $713.2(3.35)$ & $698(3.08)$ & 708.9 (3.30) & $707(3.92)$ & 692 & 686 & 688 \\
\hline $\mathrm{B}_{\mathrm{g}^{*}}^{\mathrm{g}}$ & 808.5 (3.69) & $774(3.58)$ & $786.1(4.40)$ & $771(4.30)$ & 777 & 765 & 765 \\
\hline$A_{g^{*}}^{o}$ & 916.8 (3.19) & 885 (1.63) & 906.9 (3.70) & $897(3.66)$ & 878 & 881 & 887 \\
\hline
\end{tabular}




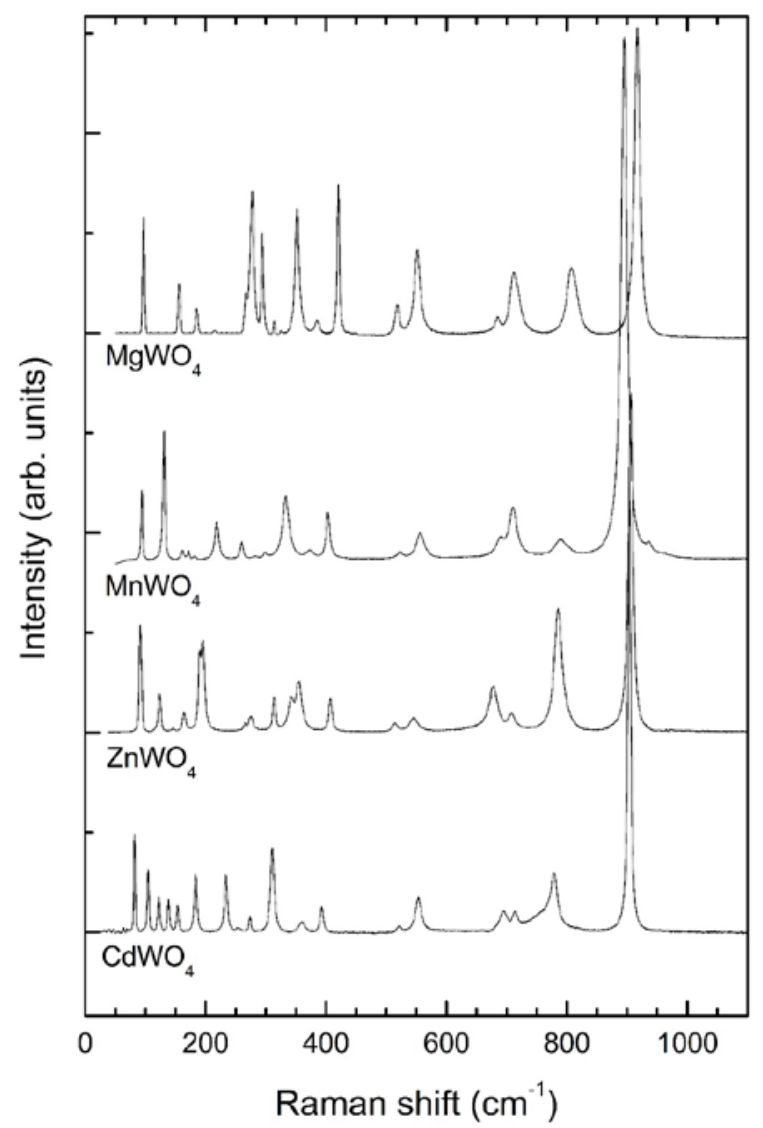

Figure 5. Raman spectra of $\mathrm{CdWO}_{4}, \mathrm{ZnWO}_{4}, \mathrm{MnWO}_{4}$, and $\mathrm{MgWO}_{4}$ at ambient conditions.

The similitude among the Raman spectra of wolframite-type tungstates can be explained, as a first approximation, by the fact that Raman modes can be classified as internal and external modes with respect to the $\mathrm{WO}_{6}$ octahedron [19]. Six internal stretching modes are expected to arise from the $\mathrm{WO}_{6}$ octahedron. Four of them should have $\mathrm{A}_{\mathrm{g}}$ symmetry and the other two $\mathrm{B}_{\mathrm{g}}$ symmetry. Since the $\mathrm{W}$ atom is heavier than any of the divalent cations in $A \mathrm{WO}_{4}$ wolframites (e.g., $\mathrm{Mg}$ or $\mathrm{Mn}$ ) and $\mathrm{W}-\mathrm{O}$ covalent bonds are less compressible than $A-\mathrm{O}$ bonds, the internal stretching modes of $\mathrm{WO}_{6}$ are the four modes in the high-frequency part of the Raman spectrum $\left(2 \mathrm{~A}_{\mathrm{g}}+2 \mathrm{~B}_{\mathrm{g}}\right)$ plus one $\mathrm{A}_{\mathrm{g}}$ mode located near $550 \mathrm{~cm}^{-1}$ and one $A_{g}$ mode with a frequency near $400 \mathrm{~cm}^{-1}$. To facilitate identification by the reader, the six internal modes are identified by an asterisk in Table 2. Notice that these six modes have pressure coefficients that do not change much from one compound to the other, and are among the largest pressure coefficients $(\mathrm{d} \omega / \mathrm{dP})$. These observations are consistent with the fact that these modes are associated with internal vibrations on the $\mathrm{WO}_{6}$ octahedron and with the well-known incompressibility of it [10], explained in the previous section.

The twelve Raman modes not corresponding to internal stretching vibrations of the $\mathrm{WO}_{6}$ octahedron imply either bending or motions of $\mathrm{WO}_{6}$ units against the divalent atom $A$. These modes are in the low-frequency region and are of particular interest because they are very sensitive to structural symmetry changes. Most of these modes (except to $B_{g}$ modes) have smaller pressure coefficients than do the internal modes. As expected, all Raman-active modes harden under compression, which indicates that the phase transitions induced by pressure are not associated with soft-mode mechanisms. A similar behavior has been reported for wolframite-type $\mathrm{MnWO}_{4}-\mathrm{FeWO}_{4}$ solid-solutions [32].

Raman spectroscopy is very sensitive to pressure-driven phase transitions in wolframites. In order to illustrate this, we show in Figure 6 a selection of Raman spectra measured in $\mathrm{MnWO}_{4}$ at different pressures. The experiments were carried out in a diamond-anvil cell using neon as a pressure medium 
to guarantee quasi-hydrostatic conditions [20]. Clear changes in the Raman spectrum are detected at 25.7 GPa. In particular, new peaks are detected. These changes are indicative of the onset of a structural phase transition. Above $25.7 \mathrm{GPa}$, gradual changes occur in the Raman spectrum-the Raman modes of the low-pressure wolframite phase only beyond 35 GPa disappear-which indicates the completion of the phase transition. In parallel, the Raman modes of the high-pressure (HP) phase steadily gain intensity from 25.7 to $35 \mathrm{GPa}$. In Figure 6, the Raman spectra reported at 37.4 and 39.3 GPa correspond to a single post-wolframite phase. In the same figure, it can be seen that the phase transition is reversible, the Raman spectrum collected at $0.5 \mathrm{GPa}$ under decompression corresponding to the wolframite phase. The number of Raman-active modes detected for this HP phase of $\mathrm{MnWO}_{4}$ is 18 (the same number as that for the wolframite-type phase). These modes have been assigned in accordance with the crystal structure proposed for the HP phase [13,31]. This structure is a triclinic distortion of wolframite, and the same number of Raman-active modes is expected; however, all of them have $\mathrm{A}_{\mathrm{g}}$ symmetry in the HP phase. Table 3 shows the frequencies of the Raman-active modes of the HP phase of $\mathrm{MnWO}_{4}$ and its pressure coefficients. A detailed discussion of the Raman spectrum of the HP phase can be found elsewhere [20] and is beyond the scope of this article. Here, we will just mention its most relevant features: (1) The modes are no longer isolated in three groups, which suggests that vibrations cannot be explained with a model that assumes that the $\mathrm{WO}_{6}$ octahedron is an isolated unit. (2) The most intense mode is the highest frequency mode (Figure 6), which indicates that it might be associated with a $\mathrm{W}-\mathrm{O}$ stretching vibration. (3) Interestingly, this mode drops in frequency in comparison to the highest frequency mode in the low-pressure wolframite phase. This is indicative of an increase in $\mathrm{W}-\mathrm{O}$ bond length evolving towards an effective increasing of the $\mathrm{W}-\mathrm{O}$ coordination. (4) All the modes of the HP phase harden under compression, but the pressure coefficients of the different modes are smaller than those in the low-pressure phase, which can be explained by the decrease in the compressibility of $\mathrm{MnWO}_{4}$.

Table 3. The Raman active modes of the HP phase of $\mathrm{MnWO}_{4}$ at $34 \mathrm{GPa}$ with their pressure coefficients.

\begin{tabular}{|c|c|c|}
\hline \multirow{2}{*}{ Mode } & \multirow{2}{*}{$\omega\left(\mathrm{cm}^{-1}\right)$} & $\mathrm{d} \omega / \mathrm{dP}$ \\
\hline & & $\left(\mathrm{cm}^{-1} \mathrm{GPa}^{-1}\right)$ \\
\hline $\mathrm{A}_{\mathrm{g}}$ & 146 & 0.8 \\
\hline$A_{g}^{\circ}$ & 186 & 0.09 \\
\hline$A_{g}^{0}$ & 196 & 1.78 \\
\hline$A_{g}^{0}$ & 217 & 1.73 \\
\hline$A_{g}^{0}$ & 242 & 1.58 \\
\hline$A_{g}$ & 292 & 0.78 \\
\hline$A_{g}^{0}$ & 314 & 1.34 \\
\hline$A_{g}^{0}$ & 370 & 2.02 \\
\hline$A_{g}^{0}$ & 388 & 2.6 \\
\hline$A_{g}$ & 446 & 2.46 \\
\hline$A_{g}^{0}$ & 495 & 1.5 \\
\hline$A_{g}^{0}$ & 511 & 1.34 \\
\hline$A_{g}^{0}$ & 586 & 1.19 \\
\hline$A_{g}$ & 676 & 1.86 \\
\hline$A_{g}^{0}$ & 710 & 1.46 \\
\hline$A_{g}^{0}$ & 784 & 1 \\
\hline$A_{g}^{0}$ & 810 & 3.26 \\
\hline $\mathrm{A}_{\mathrm{g}}$ & 871 & 0.69 \\
\hline
\end{tabular}




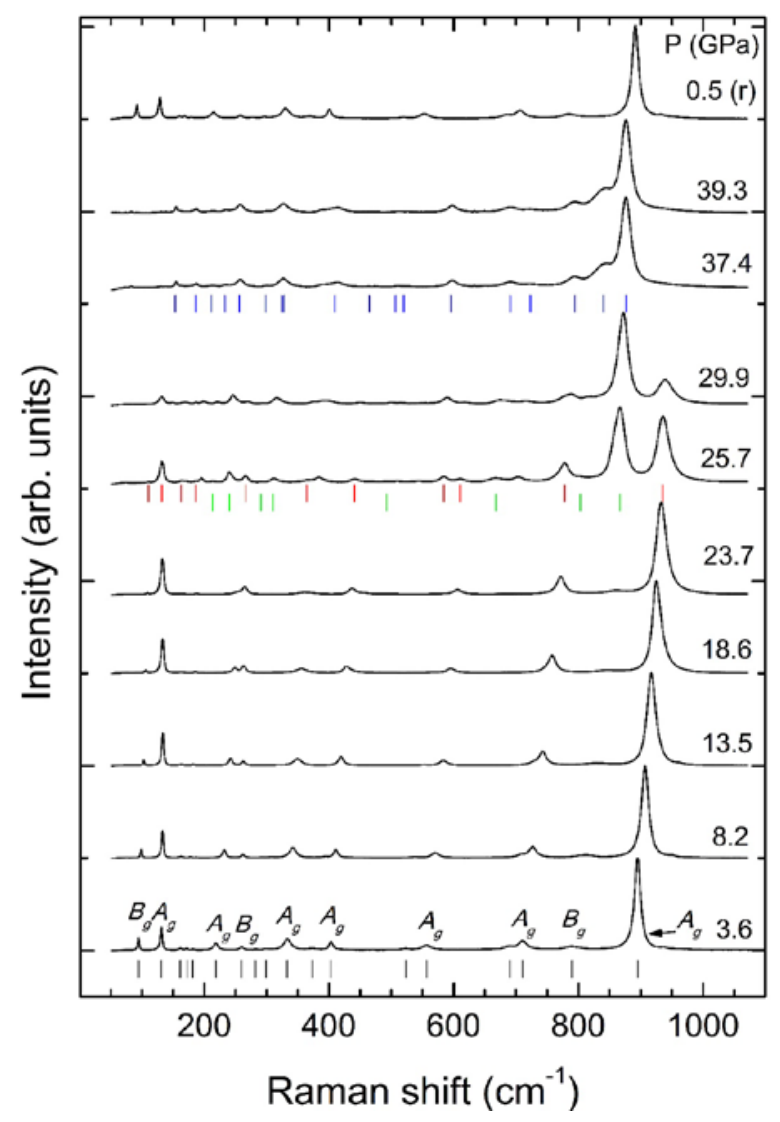

Figure 6. Raman spectra of $\mathrm{MnWO}_{4}$ at selected pressures. Raman modes of the wolframite phase are identified by ticks (and labeled) in the lowest trace (3.6 GPa). At 25.7 GPa, the modes of the low- and high-pressure phase are identified by red and green ticks, respectively. At $37.4 \mathrm{GPa}$, the ticks identify the 18 Raman-active modes of the HP phase. Pressures (in GPa) are indicated in each Raman spectrum. The spectrum labeled as $0.5(\mathrm{r})$ was collected at $0.5 \mathrm{GPa}$ after decompression.

Phase transitions are detected by Raman spectroscopy in other $A \mathrm{WO}_{4}$ tungstates from 20 to 30 GPa [17-19]. In $\mathrm{CdWO}_{4}, \mathrm{ZnWO}_{4}$, and $\mathrm{MgWO}_{4}$ phase coexistence is found between the low- and high-pressure phases in a pressure range of $10 \mathrm{GPa}$. The Raman spectra of the HP phase of all of the compounds studied up to now resemble very much those of the $\mathrm{HP}$ phase of $\mathrm{MnWO}_{4}$. However, there are small discrepancies that suggest that, even though the HP phase is structurally related to wolframite, there are some differences in their HP phases. These can be clearly seen when comparing the Raman spectra published for the HP phases of $\mathrm{CdWO}_{4}$ [18] and $\mathrm{MnWO}_{4}$ [20]. In $\mathrm{CdWO}_{4}$, the phase transition to the post-wolframite structure leads to a doubling of the unit-cell (hence, the formula unit increases from 2 to 4) [14], with the consequent increase in the number of Raman modes. They have been assigned to $19 \mathrm{Ag}_{\mathrm{g}}+17 \mathrm{~B}_{\mathrm{g}}$ modes. Out of them, only 26 modes have been observed [14,18]. The frequency of these modes and the pressure coefficients are summarized in Table 4 . These values agree very well with theoretical predictions for the monoclinic $\mathrm{HP}$ phase of $\mathrm{CdWO}_{4}$ [18]. The larger number of modes observed in the HP phase of $\mathrm{CdWO}_{4}$ in comparison with $\mathrm{MnWO}_{4}$ clearly indicates that the crystal structures of the two compounds are different. In spite of this fact, in the post-wolframite phase of $\mathrm{CdWO}_{4}$, there is a substantial drop in the frequency of the highest frequency mode (the most intense one), as observed in $\mathrm{MnWO}_{4}$ [20]. In the case of $\mathrm{CdWO}_{4}$, a clear correlation can be established between the frequency drop in this $\mathrm{W}-\mathrm{O}$ stretching mode and the increase in the tungsten-oxygen coordination number [13]. Regarding the pressure dependence of the Raman modes in post-wolframite $\mathrm{CdWO}_{4}$, in Table 4, it can be seen that, as in $\mathrm{MnWO}_{4}$, in the $\mathrm{HP}$ of $\mathrm{CdWO}_{4}$ phase the vibrational modes are less affected by compression. In the HP phase of $\mathrm{CdWO}_{4}$, there are two modes with negative 
pressure coefficients. The existence of modes with negative pressure slopes might be an indication of structural instability like that observed in related scheelite-type tungstates [33].

Table 4. The Raman-active modes of the HP phase of $\mathrm{CdWO}_{4}$ at $26.9 \mathrm{GPa}$ with their pressure coefficients. Twenty-six out of the 36 modes expected were measured.

\begin{tabular}{ccc}
\hline Mode & $\boldsymbol{\omega}\left(\mathbf{c m}^{-\mathbf{1}}\right)$ & $\mathbf{d} \boldsymbol{\omega} / \mathbf{d P}\left(\mathbf{c m}^{\mathbf{- 1}} \mathbf{G P a}^{\mathbf{- 1}}\right)$ \\
\hline $\mathrm{A}_{\mathrm{g}}$ & 69 & 1.96 \\
$\mathrm{~B}_{\mathrm{g}}$ & 88 & 1.94 \\
$\mathrm{Ag}_{\mathrm{g}}$ & 99 & 0.09 \\
$\mathrm{~B}_{\mathrm{g}}$ & 130 & 0.38 \\
$\mathrm{~A}_{\mathrm{g}}$ & 146 & 1.35 \\
$\mathrm{Ag}_{\mathrm{g}}$ & 155 & 0.97 \\
$\mathrm{~B}_{\mathrm{g}}$ & 165 & 0.19 \\
$\mathrm{~A}_{\mathrm{g}}$ & 185 & 1.26 \\
$\mathrm{~B}_{\mathrm{g}}$ & 209 & 1.26 \\
$\mathrm{Ag}_{\mathrm{g}}$ & 243 & -0.06 \\
$\mathrm{~B}_{\mathrm{g}}$ & 279 & 2.53 \\
$\mathrm{~A}_{\mathrm{g}}$ & 290 & 0.99 \\
$\mathrm{~B}_{\mathrm{g}}$ & 315 & 3.00 \\
$\mathrm{~B}_{\mathrm{g}}$ & 378 & 1.65 \\
$\mathrm{~A}_{\mathrm{g}}$ & 401 & 2.31 \\
$\mathrm{Ag}_{\mathrm{g}}$ & 428 & 3.03 \\
$\mathrm{~B}_{\mathrm{g}}$ & 475 & 2.51 \\
$\mathrm{Ag}_{\mathrm{g}}$ & 486 & 2.71 \\
$\mathrm{~B}_{\mathrm{g}}$ & 512 & 2.33 \\
$\mathrm{~B}_{\mathrm{g}}$ & 590 & 2.62 \\
$\mathrm{Ag}_{\mathrm{g}}$ & 673 & -0.82 \\
$\mathrm{Ag}_{\mathrm{g}}$ & 688 & 2.81 \\
$\mathrm{~B}_{\mathrm{g}}$ & 710 & 1.60 \\
$\mathrm{Ag}_{\mathrm{g}}$ & 766 & 2.12 \\
$\mathrm{Ag}_{\mathrm{g}}$ & 824 & 2.23 \\
$\mathrm{Ag}_{\mathrm{g}}$ & 864 & 2.04 \\
\hline
\end{tabular}

To conclude the discussion on tungstates, we would like to state that, in $\mathrm{ZnWO}_{4}$ and $\mathrm{MgWO}_{4}[7,19]$, fewer than 18 Raman modes have been found for the HP phase. The frequency distribution of Raman modes more closely resembles that of $\mathrm{MnWO}_{4}$ than that of $\mathrm{CdWO}_{4}$. However, no definitive conclusion can be stated on the structure of the $\mathrm{HP}$ phase of $\mathrm{ZnWO}_{4}$ or $\mathrm{MgWO}_{4}$ only from Raman spectroscopy measurements. Indeed, the accurate assignment of the modes of the HP phases of $\mathrm{ZnWO}_{4}$ and $\mathrm{MgWO}_{4}$ requires $\mathrm{HP}$ single-crystal experiments similar to those already carried out with $\mathrm{MnWO}_{4}$ and $\mathrm{CdWO}_{4}[13,14]$.

HP Raman studies have been also carried out for wolframite-type $\mathrm{InTaO}_{4}$ and $\mathrm{InNbO}_{4}[15,16]$. In both compounds, the Raman spectrum and its pressure evolution resemble those for the tungstates described above. Again, in the low-pressure phase, the modes that change more under compression are the highest frequency modes, which correspond to internal stretching vibrations of the $\mathrm{TaO}_{6}$ or $\mathrm{NbO}_{6}$ octahedron. In these compounds, the phase transition occurs around $15 \mathrm{GPa}$. At the transition, there is a redistribution of high-frequency modes (which seems to be a fingerprint of a transition to post-wolframite), which involves a drop in frequency in the highest frequency mode and other changes consistent with coordination changes determined by XRD experiments $[15,16]$.

\section{Electronic Structure and Band Gap}

The knowledge of the electronic band structure of wolframite-type compounds is important for the development of the technological applications of these materials. The study of the pressure effects in the band gap has been proven to be an efficient tool for testing the electronic band structure of materials. The first efforts to accurately determine the band structure of wolframites were made 
by Abraham et al. [34]. These authors focused on $\mathrm{CdWO}_{4}$, comparing it with the better known scheelite-type $\mathrm{CdMoO}_{4}$. By means of density-functional theory calculations, they found that the lowermost conduction bands of $\mathrm{CdWO}_{4}$ are controlled by the crystal-field-splitting of the $5 d$ bands of tungsten (slightly hybridized with $\mathrm{O} 2 p$ states). On the other hand, the upper part of the valence band is mainly constituted by $\mathrm{O} 2 p$ states (slightly hybridized with $\mathrm{W} 5 d$ states). As a consequence, $\mathrm{ZnWO}_{4}, \mathrm{CdWO}_{4}$, and $\mathrm{MgWO}_{4}$ have very similar band-gap energy $E_{g}$. Accurate values of $E_{g}$ have been determined by means of optical-absorption measurements, $E_{g}$ being equal to 3.98, 4.02, and $4.06 \mathrm{eV}$ in $\mathrm{ZnWO}_{4}, \mathrm{CdWO}_{4}$, and $\mathrm{MgWO}_{4}$, respectively [22]. On the contrary, $\mathrm{MnWO}_{4}$ is known to have a considerably smaller band gap, $E_{g}=2.37 \mathrm{eV}$ [22]. This distinctive behavior is the consequence of the contribution of the $\mathrm{Mn} 3 d^{5}$ orbitals to the states near the Fermi energy. Basically, $\mathrm{Mg}\left(3 s^{2}\right), \mathrm{Zn}\left(3 d^{10}\right)$, or $\mathrm{Cd}\left(4 d^{10}\right)$ have filled electronic shells and therefore do not contribute either to the top of the valence band or the bottom of the conduction band. However, in $\mathrm{MnWO}_{4}, \mathrm{Mn}\left(3 d^{5}\right)$ contributes to the top of the valence band and the bottom of the conduction band, reducing the band-gap energy in comparison to $\mathrm{ZnWO}_{4}, \mathrm{CdWO}_{4}$, and $\mathrm{MgWO}_{4}$. A similar behavior to that of $\mathrm{MnWO}_{4}$ is expected for $\mathrm{NiWO}_{4}$, $\mathrm{CoWO}_{4}$, and $\mathrm{FeWO}_{4}$ due to the presence of $\mathrm{Ni} 3 d^{8}, \mathrm{Co} 3 d^{7}$, and $\mathrm{Fe} 3 d^{6}$ states. Therefore, among the wide dispersion of values reported for $\mathrm{NiWO}_{4}\left(2.28 \mathrm{eV}<E_{g}<4.5 \mathrm{eV}\right)$ [35], those in the lowest limit appear to be the most realistic values. Notice that the above conclusions are in agreement with the fact that $\mathrm{CuWO}_{4}$, a distorted wolframite, in which $\mathrm{Cu} 3 d^{9}$ states contribute to the top of the conduction band, has a band-gap energy of $2.3 \mathrm{eV}$ [36]. Another relevant difference between the band structure of the first and second group of compounds is that it necessarily implies that $\mathrm{ZnWO}_{4}, \mathrm{CdWO}_{4}$, and $\mathrm{MgWO}_{4}$ are direct band gap materials, but the other wolframites are indirect band-gap materials [22].

An analogous behavior to that of the wolframite-tungstates is expected for isomorphic molybdates. In this case, the states near the Fermi level will be basically dominated by $\mathrm{MoO}_{4}{ }^{2-}$ [37], so wolframite-type molybdates should have slightly smaller $E_{g}$ than the tungsten-containing counterpart [38]. Unfortunately, less efforts have been dedicated to molybdates than to tungstates. However, the above stated hypothesis has been confirmed in the case of wolframite-type $\mathrm{ZnMoO}_{4}$, which has $E_{g}=3.22 \mathrm{eV}$ [39]. A similar value is expected for $\mathrm{MgMoO}_{4}$, ruling out estimations that range from 4.5 to $5.5 \mathrm{eV}$ [40]. On the other hand, the band-gap energy of $2.2 \mathrm{eV}$ determined for $\mathrm{NiMoO}_{4}$ [41] is fully consistent with the conclusions extracted from $\mathrm{MnWO}_{4}$. In this case, the $\mathrm{Ni} 3 d^{8}$ states will be responsible of the reduction of its $E_{g}$ in comparison with $\mathrm{ZnMoO}_{4}$.

$\mathrm{InTaO}_{4}$ and $\mathrm{InNbO}_{4}$ are promising materials for photocatalytic water splitting applications [42]. Both materials have been found to be indirect band-gap semiconductors, with $E_{g}=3.79 \mathrm{eV}$ in $\mathrm{InTaO}_{4}$ [16]. In this compound, the $\mathrm{O} 2 p$ states, with a small amount of mixing of the In $4 d$ states, dominate the upper part of the valence band, and Ta $5 d$ states and In $5 s$ dominate the lower conduction bands. An analogous situation is expected for $\mathrm{InNbO}_{4}$, with the only difference being that $\mathrm{Nb} 4 d$ contributes to the bottom of the conduction band and the Ta $5 d$ states do not. This fact makes $E_{g}$ slightly smaller in $\mathrm{InNbO}_{4}$ (nearly $3.4 \mathrm{eV}$ ) than in $\mathrm{InTaO}_{4}$ [43]. An explanation for this phenomenon comes from the larger Pauling's electronegativity of $\mathrm{Nb}$ (1.6) in comparison with $\mathrm{Ta}$ (1.5) [44]. Within a basic tight-binding approach, $E_{g}$ is proportional to the overlap integral between the wave functions of atoms. Since Ta has a smaller Pauling's electronegativity than $\mathrm{Nb}$, in a tantalate, the electron transfer from Ta to neighboring oxygen atoms is expected to be larger than the electron transfer from $\mathrm{Nb}$ to the neighboring oxygen atoms in a niobate. Therefore, the superposition of wave functions of $\mathrm{Ta}$ and $\mathrm{O}$ is larger than that of $\mathrm{Nb}$ and $\mathrm{O}$, resulting in a larger $E_{g}$ in $\mathrm{InTaO}_{4}$ than in $\mathrm{InNbO}_{4}$. The same argument can be used to justify the fact that, systematically, molybdates have a smaller $E_{g}$ than tungstates, which has been stated in the previous paragraph.

We shall discuss now the influence of pressure on the band structure of wolframites. We will first focus on wolframite-type tungstates. The pressure dependence of $E_{g}$ has been determined from optical-absorption experiments up to $10 \mathrm{GPa}$ for $\mathrm{CdWO}_{4}, \mathrm{MgWO}_{4}, \mathrm{MnWO}_{4}$, and $\mathrm{ZnWO}_{4}$ [22]. The experiments were carried out on single-crystal samples, under quasi-hydrostatic conditions up to a maximum pressure which is far away from the transition pressure. The obtained results are 
summarized in Figure 7. There it can be seen that $\mathrm{MnWO}_{4}$ has a very distinctive behavior. For $\mathrm{MgWO}_{4}$, $\mathrm{ZnWO}_{4}$, and $\mathrm{CdWO}_{4}$, the pressure dependence of $E_{g}$ can be represented by a linear function with a positive slope close to $\mathrm{d} E_{g} / \mathrm{d} P=13 \mathrm{meV} / \mathrm{GPa}$ [22]. However, a different pressure dependence is followed by $\mathrm{MnWO}_{4}$, in which $E_{g}$ redshifts at $-22 \mathrm{meV} / \mathrm{GPa}$ [22]. An explanation to the different

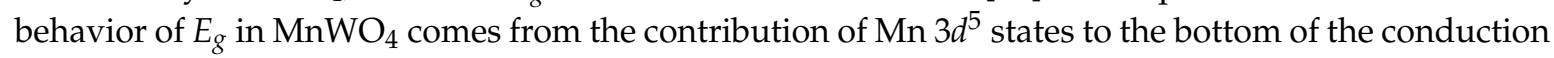
band. Whereas for $\mathrm{MgWO}_{4}, \mathrm{ZnWO}_{4}$, and $\mathrm{CdWO}_{4}$, under compression the bottom of the conduction band goes up in energy, the contribution of Mn states makes it to go down [22]. On the other hand, for the four compounds, the top of the valence band keeps the same energy. This is translated into an increase in $E_{g}$ for $\mathrm{MgWO}_{4}, \mathrm{ZnWO}_{4}$, and $\mathrm{CdWO}_{4}$ and a decrease in $E_{g}$ for $\mathrm{MnWO}_{4}$. The same behavior in $\mathrm{MnWO}_{4}$ has been reported for triclinic wolframite-related $\mathrm{CuWO}_{4}$ [35] and can be predicted for $\mathrm{CoWO}_{4}, \mathrm{FeWO}_{4}$, and $\mathrm{NiWO}_{4}$.

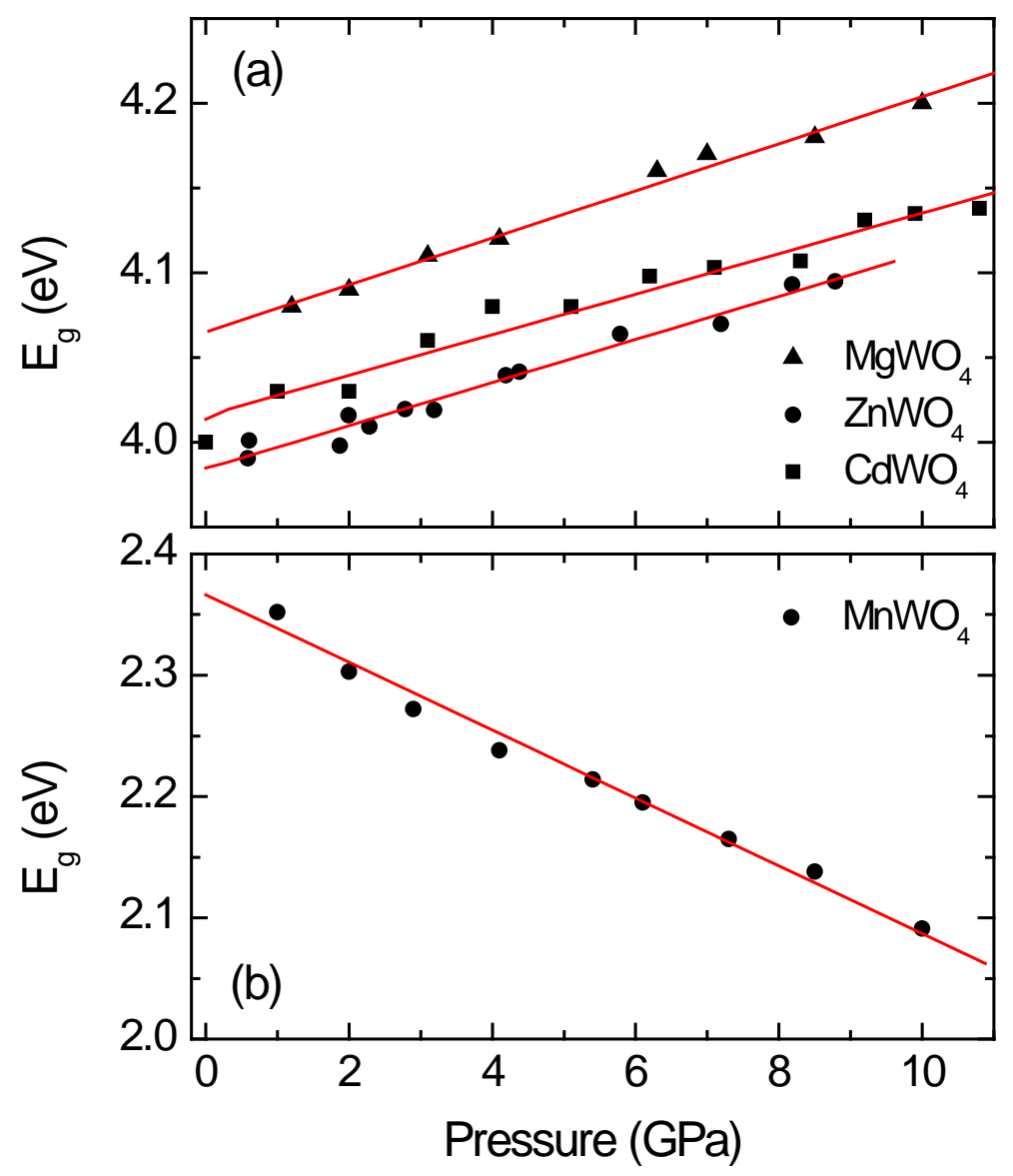

Figure 7. Pressure dependence of the band-gap energy in (a) wolframite-type $\mathrm{MgWO}_{4}, \mathrm{ZnWO}_{4}$, $\mathrm{CdWO}_{4}$, and (b) $\mathrm{MnWO}_{4}$.

The same arguments used to explain the HP behavior of the band-gap in wolframites are useful for understanding the related scheelite-type and monazite-type oxides [45]. An example of it are scheelite-type $\mathrm{CaMoO}_{4}\left(\mathrm{CaWO}_{4}\right)$ and $\mathrm{PbMoO}_{4}\left(\mathrm{PbWO}_{4}\right)[46,47]$. Another example of it is monazite-type $\mathrm{SrCrO}_{4}$ and $\mathrm{PbCrO}_{4}$ [48,49]. In all these compounds, the Pb-containing compounds have a smaller $E_{g}$ than their isomorphic compounds. This is due to the contribution of $\mathrm{Pb} 6 s(6 p)$ states to the top (bottom) of the valence (conduction) band. In addition, the Pb states make the band gap to close under compression. As a consequence, $\mathrm{d} E_{g} / \mathrm{d} P$ is negative in the $\mathrm{Pb}$ containing compounds, but has the opposite sign in the other compounds.

Studies beyond the pressure range of stability have been carried out for $\mathrm{CdWO}_{4}$ [14]. In this compound optical-absorption studies under quasi-hydrostatic conditions have been performed up 
to 23 GPa. The pressure dependence determined of $E_{g}$ is shown in Figure 8. As described above, in the first compression steps, $E_{g}$ increases with pressure. However, at $16.9 \mathrm{GPa}$, the behavior of $E_{g}$ changes, moving to lower energies under compression up to $19.5 \mathrm{GPa}$. This change is caused by a band crossing of the direct and indirect band gaps [14], this result being consistent with Raman and XRD measurements. Beyond 19.5 GPa, a drastic color change occurs in the sample as the result of a sharp band gap reduction to $\sim 3.5 \mathrm{eV}$ [14]. The changes are triggered by the onset of the structural phase transition described in a previous section. In the HP phase of $\mathrm{CdWO}_{4} E_{g}$ decreases with pressure. Regarding the slope change observed at $16.9 \mathrm{GPa}$, it is a consequence of a direct to indirect band-gap transition caused by the modification of the electronic band structure under compression $[14,50]$. Such band crossing has also been observed in other wolframites, such as $\mathrm{InTaO}_{4}$ [15]. This phenomenon should influence not only the band gap but also other band-structure parameters, such as the effective masses, having a strong influence in transport properties [51], an issue that deserves to be explored in the future.

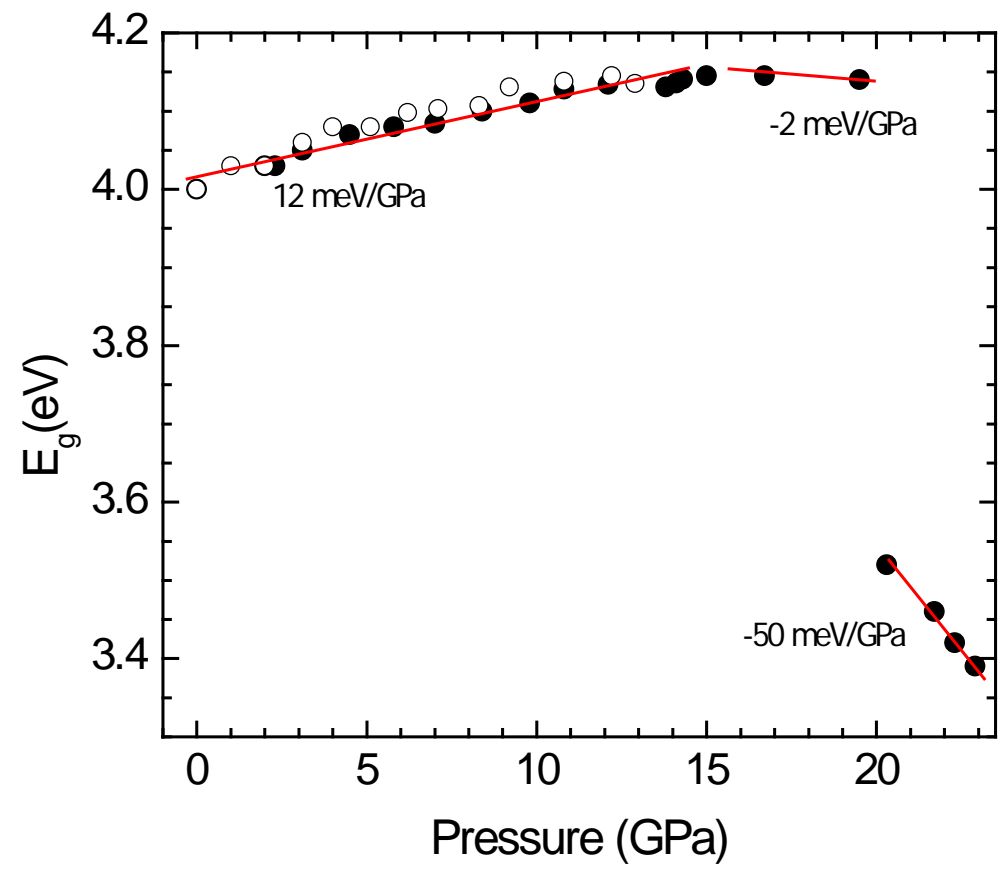

Figure 8. Pressure dependence of the band-gap energy for the low- and high-pressure phases of $\mathrm{CdWO}_{4}$.

Let us discuss now the case of $\mathrm{InTaO}_{4}$. In this compound, $E_{g}$ has been experimentally determined up to $23 \mathrm{GPa}$ [15]. Calculations have been also carried out [15]. The results are shown in Figure 9. Calculations underestimate the value of $E_{g}$, which is typical of density-functional theory; however, they nicely reproduce the pressure dependence of $E_{g}$. In the figure, it can be seen that, when pressure is increased, there is a blueshift of $E_{g}$ with a change of the $\mathrm{d} E_{g} / \mathrm{d} P$ around $5 \mathrm{GPa}$. As in $\mathrm{CdWO}_{4}$, this singularity occurs due to a band crossing [15], which in the case of $\mathrm{InTaO}_{4}$ is triggered by changes induced in the top of the valence band by pressure. In particular, at around $5 \mathrm{GPa}$, the maximum of the valence band changes from the $\mathrm{Y}$ point of the Brillouin zone to the $\mathrm{Z}$ point. On the other hand, when increasing the pressure beyond $13 \mathrm{GPa}, \mathrm{InTaO}_{4}$ changes from colorless to yellow [15]. The change in color is correlated to a band-gap collapse and is associated with a structural phase transition found by Raman and XRD experiments [15]. The HP phase has been found to have a direct band gap (the low-pressure wolframite has an indirect gap). In contrast with the low-pressure phase, in the HP phase $E_{g}$ redshifts with pressure. This is a consequence of the fact that, under compression, the valence band shifts slightly faster towards high energies than the conduction band. 

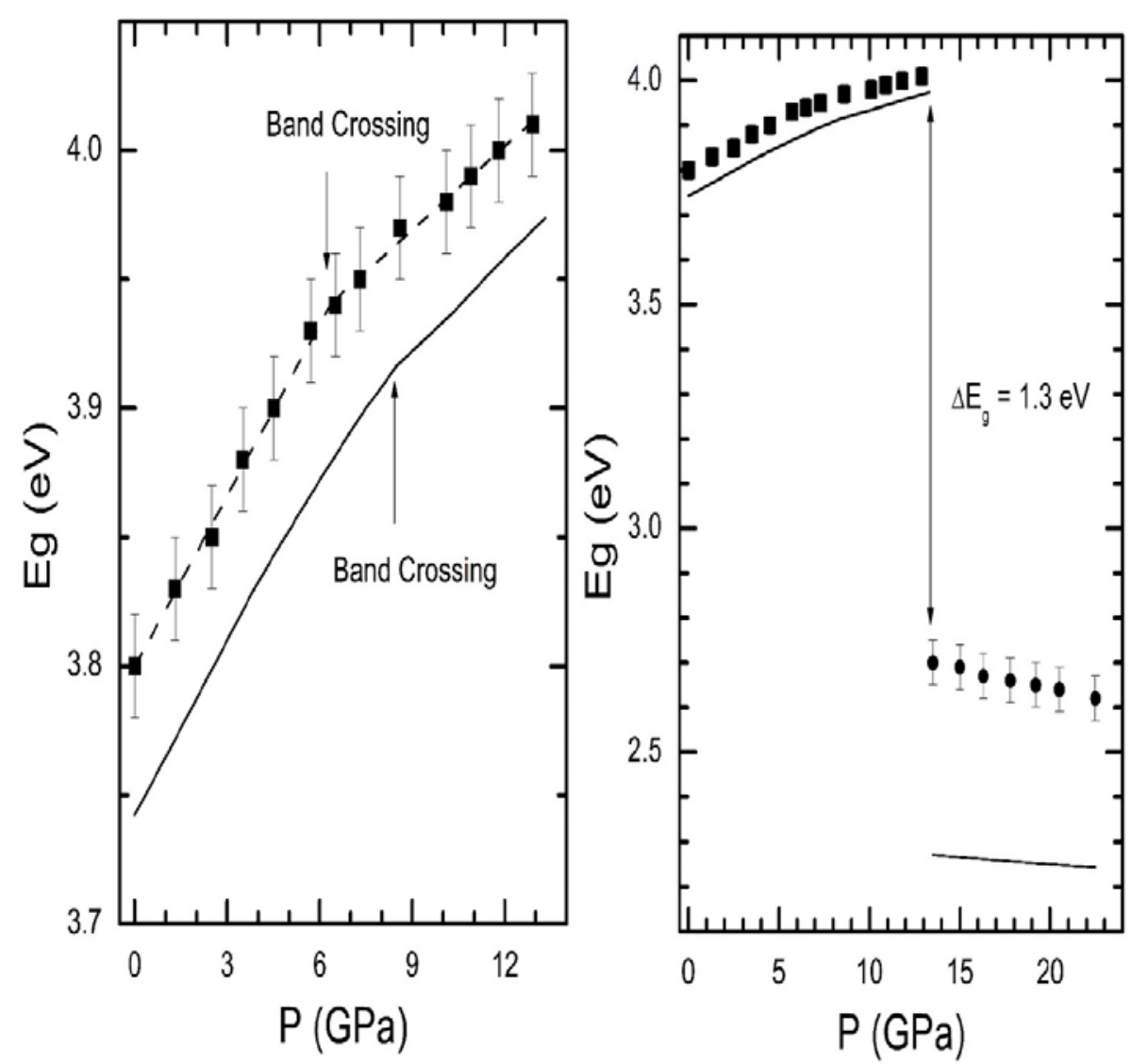

Figure 9. (left) Pressure dependence of $\mathrm{E}_{\mathrm{g}}$ in the low-pressure phase of $\mathrm{InTaO}_{4}$. The change in the pressure dependence caused by the band-crossing induced by pressure is indicated with arrows. (right) Pressure dependence of $\mathrm{E}_{\mathrm{g}}$ in the low- and high-pressure phases of $\mathrm{InTaO}_{4}$. The band-gap collapse associated with the transition is indicated $\left(\mathrm{E}_{\mathrm{g}}=1.3 \mathrm{eV}\right)$. In both figures, symbols correspond to experiments and lines to calculations.

To close this section, we would like to comment on the possible pressure-induced metallization of wolframites. It has been suggested, based upon resistivity measurements, that ternary oxides related to wolframite might metallize through band overlapping at relative low pressures (12-30 GPa) [52,53]. So far, no evidence of metallization has been detected for all the studied wolframites, either in the pressure range of stability of the low-pressure phase or in the post-wolframite phases up to the maximum pressure achieved in experiments (45 GPa in $\mathrm{ZnWO}_{4}$ and $\mathrm{CdWO}_{4}$ ) [17,18]. In particular, the sample darkening associated with a semiconductor-metal transition has never been detected in any wolframite under compression. In addition, density-functional theory calculations also exclude the possibility of metallization in the wolframite and post-wolframite phases $[14,15]$. One of the reasons preventing metallization is the robustness of the $\mathrm{WO}_{6}\left(\mathrm{MO}_{6}, \mathrm{NbO}_{6}\right.$, and $\left.\mathrm{TaO}_{6}\right)$ octahedron, which is a less compressible polyhedral unit within the crystal structure. As a consequence, the application of high pressures is not enough to increase the overlap between the electronic wave-functions of transition metals $(\mathrm{W}, \mathrm{Mo}, \mathrm{Nb}$, and $\mathrm{Ta}$ ) and oxygen atoms to broaden the electronic bands and create the eventual delocalization of the electrons requested for metallization [54]. The fact that in distorted wolframite $\mathrm{CuWO}_{4}$ a HP phase transition takes place without any significant reduction of the Jahn-Teller distortion [55] suggests that this compound is the best candidate for metallization driven by band overlap under compression. 


\section{Concluding Remarks}

In the sections presented above, we have described the recent advances made on the understanding of the structural, vibrational, and electronic properties of wolframites under compression. The discussion has mainly been based on experimental results; however, ab initio calculations have been crucial for the interpretation of experiments [12-16]. Between the recent advances, the one that has likely had more influence in the field has been the structural solution of the different post-wolframite structures. The precise knowledge of the pressure structural stability of different wolframites and their HP structures has opened two new avenues to explore: (i) the study of the scintillating properties of the HP polymorphs by means of HP photoluminescence studies; (ii) the changes produced by this structural change on the magnetic properties of those wolframites with an open $d$ outer shell like multiferroic $\mathrm{MnWO}_{4}$; and (iii) the behavior under compression of wolframite alloys like $\mathrm{MnW}_{1-\mathrm{x}} \mathrm{Mo}_{\mathrm{x}} \mathrm{O}_{4}$ [56]; in particular, $\mathrm{CdW}_{1-\mathrm{x}} \mathrm{Mo}_{x} \mathrm{O}_{4}$ whose end-members have either the wolframite or scheelite structure. For these biphasic alloy systems, their HP behavior is unpredictable [57].

In recent years, some works have appeared to deal with the pressure-temperature magnetic phase diagram of pure $[9,58]$ or cobalt alloyed [59] $\mathrm{MnWO}_{4}$. Those works have found that pressure is able to disrupt the fine equilibrium of the frustrated antiferromagnetic phase of $\mathrm{MnWO}_{4}$ (AF1) but enhance the Néel temperature of the AF3 and AF4 magnetic phases of pure or lowly Co-doped $\mathrm{MnWO}_{4}$ and highly Co-doped $\mathrm{MnWO}_{4}$, respectively. Considering the direct effect that pressure has on the spin structure that is even able to cause a spin-flop transition for highly Co-doped $\mathrm{MnWO}_{4}$ [59], one can expect a new and fascinating phase diagram in the $\mathrm{HP}$ phase of $\mathrm{MnWO}_{4}$, where distortions are expected to be higher due to the lowering of symmetry from space group $P 2 / c$ to $P \overline{1}$. So far, the only study done in this direction has been done with $\mathrm{CuWO}_{4}$; according to calculations in that study, the structural phase transition from $P 2 / c$ to $P \overline{1}$ also involves an antiferromagnetic to ferromagnetic order [60].

In summary, though some fundamental questions still remain to be completely solved, such as the crystallization of $\mathrm{CdWO}_{4}$ in wolframite structures in spite of the size of $\mathrm{Cd}$ or the atomic coordinates of the post-wolframite phase of $\mathrm{MnWO}_{4}$, this brief review shows (i) the great advances that have been done with respect to this family of compounds since the pioneering works of Macavei and Shultz [10] and Jayaraman et al. [11] and (ii) the avenues that have yet to be explored.

Acknowledgments: J. Ruiz-Fuertes thanks the Spanish Ministerio de Economía y Competitividad (MINECO) for the support through the Juan de la Cierva Program (IJCI-2014-20513). This work was supported by the Spanish MINECO, the Spanish Research Agency (AEI), and the European Fund for Regional Development (FEDER) under project number MAT2016-75586-C4-1-P. The authors are grateful to all of the collaborators who participated in the research reviewed here.

Conflicts of Interest: The authors declare no conflict of interest.

\section{References}

1. Broch, E.K. Skrifter Untersuchungen ueber Kristallstrukturen des Wloframittypus und des Scheelittypus Norske Videnskaps Akademi i Oslo. Mat. Nat. Kl. 1929, 8, 20.

2. Keeling, R.O., Jr. The structure of $\mathrm{NiWO}_{4}$. Acta Crystallogr. 1957, 10, 209-213. [CrossRef]

3. Young, A.P.; Schwartz, C.M. High-pressure synthesis of molybdates with the wolframite structure. Science 1963, 141, 348. [CrossRef] [PubMed]

4. Rathee, S.; Tu, D.; Monajemi, T.T.; Rickey, D.W.; Fallone, B.G. A bench-top megavoltage fan-beam CT using $\mathrm{CdWO}_{4}$-photodiode detectors. I. System description and detector characterization. Med. Phys. 2006, 33, 1078-1089. [CrossRef] [PubMed]

5. Mikhailik, V.B.; Kraus, H. Performance of scintillation materials at cryogenic temperatures. Phys. Status Solidi B 2010, 247, 1583-1599. [CrossRef]

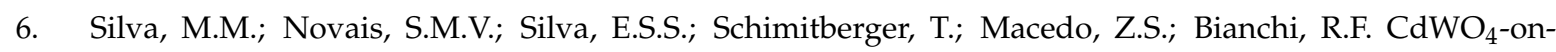
MEH-PPV:PS as a candidate for real-time dosimeters. Mater. Chem. Phys. 2012, 136, 317-319. [CrossRef] 
7. Burachas, S.P.; Danevich, F.A.; Georgadze, A.S.; Klapdor-Kleingrothaus, H.V.; Kobychev, V.V.; Kropivyansky, B.N.; Kuts, V.N.; Muller, A.; Muzalevsky, V.V.; Nikolaiko, A.S.; et al. Large volume $\mathrm{CdWO}_{4}$ crystal scintillators. Nucl. Instrum. Methods Phys. Res. Sect. A 1996, 369, 164-168. [CrossRef]

8. Lautenschläger, G.; Weitzel, H.; Vogt, T.; Hock, R.; Böhm, A.; Bonnet, M.; Fuess, H. Magnetic phase transitions of $\mathrm{MnWO}_{4}$ studied by the use of neutron diffraction. Phys. Rev. B 1993, 48, 6087. [CrossRef]

9. Chaudhury, R.P.; Yen, F.; de la Cruz, C.R.; Lorenz, B.; Wang, Y.Q.; Sun, Y.Y.; Chu, C.W. Thermal expansion and pressure effect in $\mathrm{MnWO}_{4}$. Physica B 2008, 403, 1428-1430. [CrossRef]

10. Macavei, J.; Schulz, H. The crystal structure of wolframite type tungstates at high pressure. Z. Kristallogr. 1993, 207, 193-208.

11. Jayaraman, A.; Wang, S.Y.; Sharma, S.K. New pressure-induced phase changes in $\mathrm{CdWO}_{4}$ from Raman spectroscopic and optical microscopic studies. Curr. Sci. 1995, 69, 44-48.

12. Ruiz-Fuertes, J.; López-Moreno, S.; Errandonea, D.; Pellicer-Porres, J.; Lacomba-Perales, R.; Segura, A.; Rodríguez-Hernández, P.; Muñoz, A.; Romero, A.H.; González, J. High-pressure phase transitions and compressibility of wolframite-type tungstates. J. Appl. Phys. 2010, 107, 083506. [CrossRef]

13. Ruiz-Fuertes, J.; Friedrich, A.; Gomis, O.; Errandonea, D.; Morgenroth, W.; Sans, J.A.; Santamaría-Pérez, D. High-pressure structural phase transition in $\mathrm{MnWO}_{4}$. Phys. Rev. B 2015, 91, 104109. [CrossRef]

14. Ruiz-Fuertes, J.; Friedrich, A.; Errandonea, D.; Segura, A.; Morgenroth, W.; Rodríguez-Hernández, P.; Muñoz, A.; Meng, Y. Optical and structural study of the pressure-induced phase transition of $\mathrm{CdWO}_{4}$. Phys. Rev. B 2017, 95, 174105. [CrossRef]

15. Errandonea, D.; Popescu, C.; Garg, A.B.; Botella, P.; Martínez-García, D.; Pellicer-Porres, J.; Rodríguez-Hernández, P.; Muñoz, A.; Cuenca-Gotor, V.; Sans, J.A. Pressure-induced phase transition and band-gap collapse in the wide-band-gap semiconductor $\mathrm{InTaO}_{4}$. Phys. Rev. B 2016, 93, 35204. [CrossRef]

16. Garg, A.B.; Errandonea, D.; Popescu, C.; Martínez-García, D.; Pellicer-Porres, J.; Rodríguez-Hernández, P.; Muñoz, A.; Botella, P.; Cuenca-Gotor, V.P.; Sans, J.A. Pressure-Driven Isostructural Phase Transition in $\mathrm{InNbO}_{4}$ : In Situ Experimental and Theoretical Investigations. Inorg. Chem. 2017, 56, 5420-5430. [CrossRef] [PubMed]

17. Errandonea, D.; Manjón, F.J.; Garro, N.; Rodríguez-Hernández, P.; Radescu, S.; Mujica, A.; Muñoz, A.; Tu, C.Y. Combined Raman scattering and ab initio investigation of pressure-induced structural phase transitions in the scintillator $\mathrm{ZnWO}_{4}$. Phys. Rev. B 2008, 78, 54116. [CrossRef]

18. Lacomba-Perales, R.; Errandonea, D.; Martínez-García, D.; Rodríguez-Hernández, P.; Radescu, S.; Mújica, A.; Muñoz, A.; Chervin, J.C.; Polian, A. Phase transitions in wolframite-type $\mathrm{CdWO}_{4}$ at high pressure studied by Raman spectroscopy and density-functional theory. Phys. Rev. B 2009, 79, 94105. [CrossRef]

19. Ruiz-Fuertes, J.; Errandonea, D.; López-Solano, S.; González, J.; Gomis, O.; Vilaplana, R.; Manjón, F.J.; Muñoz, A.; Rodríguez-Hernández, P.; Friedrich, A.; et al. High-pressure Raman spectroscopy and lattice-dynamics calculations on scintillating $\mathrm{MgWO}_{4}$ : Comparison with isomorphic compounds. Phys. Rev. B 2011, 83, 214112. [CrossRef]

20. Ruiz-Fuertes, J.; Gomis, O.; Errandonea, D.; Friedrich, A.; Manjón, F.J. Room-temperature vibrational properties of multiferroic $\mathrm{MnWO}_{4}$ under quasi-hydrostatic compression up to $39 \mathrm{GPa}$. J. Appl. Phys. 2014, 115, 43510. [CrossRef]

21. Dai, R.C.; Ding, X.; Wang, Z.P.; Zhang, Z.M. Pressure and temperature dependence of Raman scattering of $\mathrm{MnWO}_{4}$. Chem. Phys. Lett. 2013, 586, 76-80. [CrossRef]

22. Ruiz-Fuertes, J.; López-Moreno, S.; López-Solano, J.; Errandonea, D.; Segura, A.; Lacomba-Perales, R.; Muñoz, A.; Radescu, S.; Rodríguez-Hernández, P.; Gospodinov, M.; et al. Pressure effects on the electronic and optical properties of $\mathrm{AWO}_{4}$ wolframites $(\mathrm{A}=\mathrm{Cd}, \mathrm{Mg}, \mathrm{Mn}$, and $\mathrm{Zn})$ : The distinctive behavior of multiferroic $\mathrm{MnWO}_{4}$. Phys. Rev. B 2012, 86, 125202. [CrossRef]

23. Ruiz-Fuertes, J.; Friedrich, A.; Pellicer-Porres, J.; Erradonea, D.; Segura, A.; Haussühl, E.; Tu, C.-Y.; Polian, A. Structure Solution of the High-Pressure Phase of $\mathrm{CuWO}_{4}$ and Evolution of the JahnTeller Distortion. Chem. Mater. 2011, 23, 4220-4226. [CrossRef]

24. Goncharov, A. Raman Spectroscopy at High Pressures. Int. J. Spectrosc. 2012, 2012, 617528. [CrossRef]

25. Fomichev, V.V.; Kondratov, O.I. Vibrational spectra of compounds with the wolframite structure. Spectrochim. Acta A 1994, 50, 1113-1120. [CrossRef] 
26. Crane, M.; Frost, R.L.; Williams, P.A.; Kloprogge, J.T. Raman spectroscopy of the molybdate minerals chillagite (tungsteinian wulfenite-I4), stolzite, scheelite, wolframite and wulfenite. J. Raman Spectrosc. 2002, 33, 62-66. [CrossRef]

27. Kanesake, I.; Hashiba, H.; Matsumura, I. Polarized Raman spectrum and normal coordinate analysis of $\alpha-\mathrm{MnMoO}_{4}$. J. Raman Spectrosc. 1988, 19, 213-218. [CrossRef]

28. Coelho, M.N.; Freire, P.T.C.; Maczka, M.; Luz-Lima, C.; Saraiva, G.D.; Paraguassu, W.; Filho, A.G.S.; Pizani, P.S. High-pressure Raman scattering of $\mathrm{MgMoO}_{4}$. Vib. Spectrosc. 2013, 68, 34-39. [CrossRef]

29. De Moura, A.P.; de Oliveira, L.H.; Pereira, P.F.S.; Rosa, I.L.V.; Li, M.S.; Longo, E.; Varela, J.A. Structural, Optical, and Magnetic Properties of $\mathrm{NiMoO}_{4}$ Nanorods Prepared by Microwave Sintering. Adv. Chem. Eng. Sci. 2012, 2, 465.

30. Iliev, M.N.; Gospodinov, M.M.; Litvinchuk, A.P. Raman spectroscopy of $\mathrm{MnWO}_{4}$. Phys. Rev. B 2009, 80, 212302. [CrossRef]

31. Errandonea, D.; Pellicer-Porres, J.; Martínez-García, D.; Ruiz-Fuertes, J.; Friedrich, A.; Morgenroth, W.; Popescu, C.; Rodríguez-Hernández, P.; Muñoz, A.; Bettinelli, M. Phase Stability of Lanthanum Orthovanadate at High Pressure. J. Phys. Chem. C 2016, 120, 13749. [CrossRef]

32. Maczka, M.; Ptak, M.; da Silva, K.P.; Freire, P.T.C.; Hanuza, J. High-pressure Raman scattering and an anharmonicity study of multiferroic wolframite-type $\mathrm{Mn}_{0.97} \mathrm{Fe}_{0.03} \mathrm{WO}_{4}$. J. Phys. Condens. Matter 2012, 4, 345403. [CrossRef] [PubMed]

33. Errandonea, D.; Manjon, F.J. On the ferroelastic nature of the scheelite-to-fergusonite phase transition in orthotungstates and orthomolybdates. Mater. Res. Bull. 2009, 44, 807-811. [CrossRef]

34. Abraham, Y.; Holzwarth, N.A.W.; Williams, R.T. Electronic structure and optical properties of $\mathrm{CdMoO}_{4}$ and $\mathrm{CdWO}_{4}$. Phys. Rev. B 2000, 62, 1733. [CrossRef]

35. Zawawi, S.M.M.; Yahya, R.; Hassan, A.; Mahmud, H.N.M.E.; Daud, M.N. Structural and optical characterization of metal tungstates $\left(\mathrm{MWO}_{4} ; \mathrm{M}=\mathrm{Ni}, \mathrm{Ba}, \mathrm{Bi}\right)$ synthesized by a sucrose-templated method. Chem. Cent. J. 2013, 7, 80. [CrossRef] [PubMed]

36. Ruiz-Fuertes, J.; Errandonea, D.; Segura, A.; Manjón, F.J.; Zhu, Z.; Tu, C.Y. Growth, characterization, and high-pressure optical studies of $\mathrm{CuWO}_{4}$. High Press. Res. 2008, 28, 565-570. [CrossRef]

37. Errandonea, D. Comment on "Molten salt synthesis of barium molybdate and tungstate microcrystals". Mater. Lett. 2009, 63, 160-161. [CrossRef]

38. Lacomba-Perales, R.; Ruiz-Fuertes, J.; Errandonea, D.; Martınez-Garcia, D.; Segura, A. Optical absorption of divalent metal tungstates: Correlation between the band-gap energy and the cation ionic radius. EPL 2008, 83, 37002. [CrossRef]

39. Cavalcante, L.S.; Moraes, E.; Almeida, M.A.P.; Dalmaschio, C.J.; Batista, N.C.; Varela, J.A.; Longo, E.; Li, M.S.; Andrés, J.; Beltrán, A. A combined theoretical and experimental study of electronic structure and optical properties of $\beta-\mathrm{ZnMoO}_{4}$ microcrystals. Polyhedron 2013, 54, 13-25. [CrossRef]

40. Spasskii, D.A.; Kolobanov, V.N.; Mikhailin, V.V.; Berezovskaya, L.Y.; Ivleva, L.I.; Voronina, I.S. Luminescence peculiarities and optical properties of $\mathrm{MgMoO}_{4}$ and $\mathrm{MgMoO}_{4}: \mathrm{Yb}$ crystals. Opt. Spectrosc. 2009, 106, 556-563. [CrossRef]

41. De Moura, A.P.; de Oliveira, L.H.; Rosa, I.L.V.; Xavier, C.S.; Lisboa-Filho, P.N.; Li, M.S.; la Porta, F.A.; Longo, E.; Varela, J.A. Structural, Optical, and Magnetic Properties of $\mathrm{NiMoO}_{4}$ Nanorods Prepared by Microwave Sintering. Sci. World J. 2015, 2015, 315084. [CrossRef] [PubMed]

42. Zou, Z.; Ye, J.; Sayana, K.; Arakawa, H. Direct splitting of water under visible light irradiation with an oxide semiconductor photocatalyst. Nature 2001, 414, 625. [CrossRef] [PubMed]

43. Li, G.L.; Yin, Z. Theoretical insight into the electronic, optical and photocatalytic properties of $\operatorname{InMO}_{4}(\mathrm{M}=\mathrm{V}$, $\mathrm{Nb}, \mathrm{Ta}$ ) photocatalysts. Phys. Chem. Chem. Phys. 2011, 13, 2824-2833. [CrossRef] [PubMed]

44. Pauling, L. The energy of single bonds and the relative electronegativity of atoms. J. Am. Chem. Soc. 1932, 54, 3570-3582. [CrossRef]

45. Errandonea, D. High-pressure phase transitions and properties of $\mathrm{MTO}_{4}$ compounds with the monazite-type structure. Phys. Status Solidi B 2017, 254, 1700016. [CrossRef]

46. Panchal, V.; Garg, N.; Poswal, H.K.; Errandonea, D.; Rodríguez-Hernández, P.; Muñoz, A.; Cavalli, E. The high-pressure behavior of $\mathrm{CaMoO}_{4}$. Phys. Rev. Mater. 2017, 1, 43605. [CrossRef] 
47. Lacomba-Perales, R.; Errandonea, D.; Segura, A.; Ruiz-Fuertes, J.; Rodríguez-Hernández, P.; Radescu, S.; Lopez-Solano, J.; Mujica, A.; Muñoz, A. A combined high-pressure experimental and theoretical study of the electronic band-structure of scheelite-type $\mathrm{AWO}_{4}(\mathrm{~A}=\mathrm{Ca}, \mathrm{Sr}, \mathrm{Ba}, \mathrm{Pb})$ compounds. J. Appl. Phys. 2011, 110, 43703. [CrossRef]

48. Bandiello, E.; Errandonea, D.; Martinez-Garcia, D.; Santamaria-Perez, D.; Manjón, F.J. Effects of high-pressure on the structural, vibrational, and electronic properties of monazite-type $\mathrm{PbCrO}_{4}$. Phys. Rev. B 2012, 85, 24108. [CrossRef]

49. Gleissner, J.; Errandonea, D.; Segura, A.; Pellicer-Porres, J.; Hakeem, M.A.; Proctor, J.E.; Raju, S.V.; Kumar, R.S.; Rodríguez-Hernández, P.; Muñoz, A.; et al. Monazite-type $\mathrm{SrCrO}_{4}$ under compression. Phys. Rev. B 2016, 94, 134108. [CrossRef]

50. Baj, M.; Dmowski, L.H.; Slupinski, T. Direct proof of two-electron occupation of Ge-DX centers in GaAs codoped with Ge and Te. Phys. Rev. Lett. 1993, 71, 3529. [CrossRef] [PubMed]

51. Errandonea, D.; Segura, A.; Manjon, F.J.; Chevy, A. Transport measurements in InSe under high pressure and high temperature: Shallow-to-deep donor transformation of Sn related donor impurities. Semicond. Sci. Technol. 2003, 18, 241. [CrossRef]

52. Garg, A.B.; Shanavas, K.V.; Wani, B.N.; Sharma, S.M. Phase transition and possible metallization in $\mathrm{CeVO}_{4}$ under pressure. J. Solid State Chem. 2013, 203, 273-280. [CrossRef]

53. Duclos, S.J.; Jayaraman, A.; Espinosa, G.P.; Oxper, A.S.; Maines, R.G. Raman and optical absorption studies of the pressure-induced zircon to scheelite structure transformation in $\mathrm{TbVO}_{4}$ and $\mathrm{DyV0}_{4}$. J. Phys. Chem. Solids 1989, 8, 769-775. [CrossRef]

54. Patterson, J.R.; Aracne, C.M.; Jackson, D.D.; Malba, V.; Weir, S.T. Pressure-induced metallization of the Mott insulator MnO. Phys. Rev. B 2004, 69, 220101(R). [CrossRef]

55. Ruiz-Fuertes, J.; Segura, A.; Rodríguez, F.; Errandonea, D.; Sanz-Ortiz, M.N. Anomalous High-Pressure Jahn-Teller Behavior in $\mathrm{CuWO}_{4}$. Phys. Rev. Lett. 2012, 108, 166402. [CrossRef] [PubMed]

56. Blanco-Gutierrez, V.; Demourgues, A.; Lebreau, E.; Gaudon, M. You have full text access to this content Phase transitions in $\mathrm{Mn}\left(\mathrm{Mo}_{1-\mathrm{x}} \mathrm{W}_{\mathrm{x}}\right) \mathrm{O}_{4}$ oxides under the effect of high pressure and temperature. Phys. Status Solids B 2016, 253, 2043-2048. [CrossRef]

57. Taoufyq, A.; Guinneton, F.; Valmalette, J.C.; Arab, M.; Benlhachemi, A.; Bakiz, B.; Villain, S.; Lyoussi, A.; Nolibe, G.; Gavarri, J.R. Structural, vibrational and luminescence properties of the (1-x)CaWO $4-\mathrm{xCdWO}_{4}$ system. J. Solid State Chem. 2014, 219, 127-137. [CrossRef]

58. Hardy, V.; Payen, C.; Damay, F.; Meddar, L.; Josse, M.; Andre, G. Phase transitions and magnetic structures in $\mathrm{MnW}_{1-\mathrm{x}} \mathrm{Mo}_{\mathrm{x}} \mathrm{O}_{4}$ compounds $(\mathrm{x} \leq$ 0.2). J. Phys. Condens. Matter 2016, 28, 33600359. [CrossRef] [PubMed]

59. Wang, J.; Ye, F.; Chi, S.; Fernandez-Baca, J.A.; Cao, H.; Tian, W.; Gooch, M.; Poudel, N.; Wang, Y.; Lorenz, B.; et al. Pressure effects on magnetic ground states in cobalt-doped multiferroic $\mathrm{Mn}_{1-\mathrm{x}} \mathrm{Co}_{\mathrm{x}} \mathrm{WO}_{4}$. Phys. Rev. B 2016, 93, 155164. [CrossRef]

60. Ruiz-Fuertes, J.; Errandonea, D.; Lacomba-Perales, R.; Segura, A.; González, J.; Rodríguez, F.; Manjón, F.J.; Ray, S.; Rodríguez-Hernández, P.; Muñoz, A.; et al. High-pressure structural phase transitions in $\mathrm{CuWO}_{4}$. Phys. Rev. B 2010, 81, 224115. [CrossRef]

(C) 2018 by the authors. Licensee MDPI, Basel, Switzerland. This article is an open access article distributed under the terms and conditions of the Creative Commons Attribution (CC BY) license (http:/ / creativecommons.org/licenses/by/4.0/). 